\title{
Multifactor Evaluation of Multiple Service Support and Optimization of Working Resistance of New Support Based on Dynamic Pressure
}

\author{
Fulian He, ${ }^{1,2}$ Liang Li $\mathbb{D}_{\text {, }}^{1,2}$ Wenrui He, ${ }^{1,2}$ Xiaobin Li, ${ }^{1,2}$ Kai Lv, ${ }^{1,2}$ Binbin Qin, ${ }^{1,2}$ \\ and $\mathrm{Xuhui} \mathrm{Xu}^{1,2}$ \\ ${ }^{1}$ School of Energy \& Mining Engineering, China University of Mining \& Technology-Beijing, Beijing 100083, China \\ ${ }^{2}$ Beijing Key Laboratory for Precise Mining of Intergrown Energy and Resources, \\ China University of Mining \& Technology-Beijing, Beijing 100083, China
}

Correspondence should be addressed to Liang Li; liangli96@foxmail.com

Received 25 May 2020; Revised 5 July 2020; Accepted 10 July 2020; Published 4 August 2020

Academic Editor: Xuesheng Liu

Copyright (c) 2020 Fulian He et al. This is an open access article distributed under the Creative Commons Attribution License, which permits unrestricted use, distribution, and reproduction in any medium, provided the original work is properly cited.

The scientific and feasible method is extremely important for the evaluation of whether the support of coal mines needs to be scrapped, but it has not been formed. If the support cannot be continued to use, the determined reasonable working resistance of the support before the primary mining of coal seam should be optimized. Based on the field measurement and theoretical analysis, the concept of the actual rated working resistance of the support is proposed and analyzed accurately; the total amount of roof subsidence of circulating multiple coal cutting cycles during periodic pressure is calculated; the support performance is evaluated by multifactors; a new method for determining the reasonable working resistance of the support based on dynamic pressure is proposed. The study found that the safety valve of support is opened in advance and the resistance loss rate is large; the total amount of roof subsidence during periodic pressure is high; FAHP + EWM evaluation score of support system performance is 63.31 points. The scientific evaluation of multifactors showed that the support has reached service life, and as a result, the new 105 working faces required replacement with new support. The reasonable working resistance of the support in the 3-1 coal seam is optimized according to the new method based on dynamic pressure. This study can greatly improve the safety of roof control in the working face.

\section{Introduction}

In coal mining, roof control in the mining area is particularly critical [1-10]. The hydraulic support plays a direct role in controlling the roof of the working face and is the key equipment to ensure the safety of the working face. But the support is expensive, so coal mine should make the support serve as many working faces as possible under the condition of ensuring the safety of the control roof. The support has been serviced and several working faces are defined as multiple service support. Technicians of coal mine mostly adopt experience to judge whether to eliminate multiple service support, which lacks scientific nature. Therefore, it is extremely important to formulate the scientific and feasible method to evaluate the support performance scientifically. At the same time, due to the lack of on-site measured mine pressure data in the selection support of coal seam primary mining, only reasonable working resistance of the support can be calculated through theoretical analysis, but there is a certain discrepancy between theoretical analysis and actual engineering parameters, so more reasonable working resistance of the support can be determined through the measured mine pressure data for the working face of roof safety.

Domestic and foreign scholars have carried out extensive research in terms of support performance, service life of support, and support resistance selection. The mechanical model of "transfer rock beam" is established, and two working states of support to control the basic roof are 
proposed [11-14]. Some studies point out that the working resistance of the support has hyperbolic relation with the roof subsidence of working face [15-18]. Wang et al. [19] and Kong and Yang [20] analyzed that the working resistance of the support should meet the requirements of the coal wall. Some evaluation and analysis methods are also used in engineering evaluation [21-24], and it is used to predict and evaluate support life based on the mechanical structure damage $[25,26]$, and it is used to evaluate quantitatively the system performance to get the performance level $[27,28]$. Du [29] adopted the fuzzy comprehensive analysis method to establish the evaluation model to deal with a series of fuzzy factors affecting the working condition of the support. $\mathrm{Xu}$ and $\mathrm{Li}$ [30] used the analytic hierarchy process to calculate the weight of the factors that affect the risk of water and mud inrush in karst tunnel and carried out risk assessment to effectively control the risk. Some scholars have proposed the method of support selection [31-34]. Wang et al. [31, 32] proposed a method of support resistance selection based on two control factors. Li et al. [33] determined the reasonable working resistance of the support in the fully mechanized face with large mining height based on the key layer theory.

Previous studies did not analyze the actual resistance performance of support and the total amount of roof subsidence. Support life is just studied by the mechanical fatigue without considering the condition of working face. The problem of whether the support can be continued to serve in the same coal seam under many factors is not solved. It is necessary to make a profound study to solve this problem. At the same time, when the support is determined to be unable to continue to serve for the next working face of the same coal seam after evaluation, the more reasonable working resistance of the support can be optimized based on the measured pressure data of dynamic pressure.

In the 3-1 coal seam of Gaotouyao coal mine, the multiple support is working in 103 working faces. As the resistance performance of multiple service support is declined and the roof subsidence is obvious, and the 105 working face of 3-1 coal seam will continue to be mined, the problem that judges whether multiple service support can be continued to use in the 105 working face needs to be solved. In this paper, the method for evaluating multiple service support and a new method for optimizing reasonable working resistance of the support are proposed. This study scientifically evaluates the support performance of multiple service support through multifactors to judge whether it can be continued to work, and optimizes the determined reasonable working resistance of the support through the theoretical analysis and calculation before the primary mining of 3-1 coal seam by the new method based on the measured mine pressure data. This study can greatly improve the safety of roof control in the working face.

\section{Engineering Background}

Gaotouyao coal mine's 103 working face is the fourth working face of 3-1 coal seam. The average mining height is
$4 \mathrm{~m} .103$ and 105 working faces adopt the strike long-wall one-time full-height mining method, and the roof management adopts the full caving method. Borehole histogram in 103 working face is shown in Figure 1.

The hydraulic support is of double-column shield type with 174 sets in total. The initial support resistance of the support is $7913 \mathrm{kN}$, and the rated working resistance is $10500 \mathrm{kN}$. At present, the supports which have been used in three working faces for five years are used in 103 working face now. During the mining period of 103 working face, the opening rate of support safety valve is high during periodic pressure, and rib spalling and roof falling are obvious, as shown in Figure 2.

According to the field investigation, it is found that most of the supports in 103 working face leak without maintaining pressure, and technicians have failed to repair the supports for many times. Based on the monitoring data, it is showed that the safety valve is opened in advance and the resistance loss rate is large. The multiple service support is urgent to confirm whether it can continue to be used in the 105 working face because 105 working is close to production. Due to the lack of mine pressure data in the primary mining of 3-1 coal seam, the reasonable working resistance of the support is calculated through theoretical analysis, but there is a certain difference between the theoretical analysis and the actual engineering parameters. With the increase of the service time of the support, the resistance performance of the support will be declined, and the relationship between the service time and the performance degradation of support may not be considered in the initial determination of the working resistance of this batch of supports; therefore, the rated working resistance $F=10500 \mathrm{kN}$ may not be the best choice. It is necessary to redetermine the reasonable working resistance of the support.

\section{Mine Pressure Monitoring}

In order to master the working resistance of multiple service support and mine pressure of 103 working face, the mine pressure monitoring is mainly divided into two parts: one is to use the roof pressure monitoring substation to monitor the working resistance of the support, and the equipment is shown in Figure 3; the other is to carry out the macromonitoring of 103 working face, including the shrinkage of the left and right columns of the support, the opening of the safety valve, the mining height, the end-face distance, rib spalling, roof falling, and support pitch angle.

3.1. Layout of Monitoring Stations. The layout of monitoring stations for working resistance of supports is of centralized type in different regions. Due to the serious leakage of many supports and the columns without maintaining pressure, 19 monitoring stations are selected as far as possible to meet the requirements of a centralized layout under the guidance of the support technicians. The layout of monitoring stations and onsite personnel monitoring are shown in Figure 4. The monitoring stations of movable column shrinkage are consistent with the monitoring station of support working resistance. 


\begin{tabular}{|c|c|c|c|c|c|}
\hline Column & Rock type & Thickness (m) & Tension (MPa) & $\begin{array}{c}\text { Accumulated } \\
\text { thickness (m) }\end{array}$ & $\begin{array}{c}\text { Burying } \\
\text { depth (m) }\end{array}$ \\
\hline & Sandy mudstone & 6.95 & 1.0 & 43.50 & 162.65 \\
\hline & Fine sandstone & 2.5 & 0.3 & 36.55 & 169.60 \\
\hline & Sandy mudstone & 3.5 & 1.0 & 34.05 & 172.10 \\
\hline & Siltstone & 1.75 & 0.4 & 30.55 & 175.60 \\
\hline & Sandy mudstone & 5.0 & 1.0 & 28.80 & 177.35 \\
\hline & Fine sandstone & 3.4 & 0.3 & 23.80 & 182.35 \\
\hline & Sandy mudstone & 8.4 & 1.2 & 14.40 & 185.75 \\
\hline & Siltstone & 1.55 & 0.4 & 6.00 & 194.15 \\
\hline & Sandy mudstone & 4.45 & 1.2 & 4.45 & 195.70 \\
\hline
\end{tabular}

Figure 1: Borehole histogram in 103 working face.

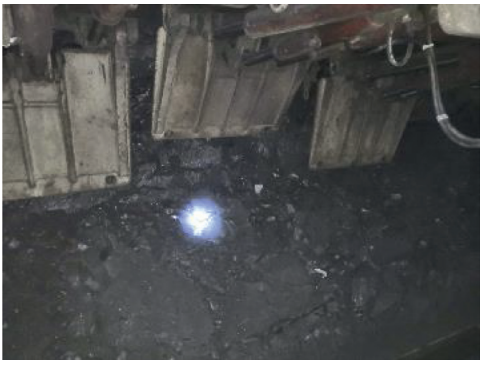

(a)

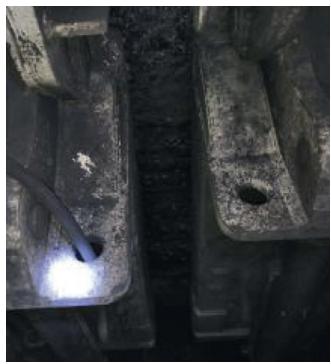

(b)

Figure 2: (a) Rib spalling and (b) roof falling on site.

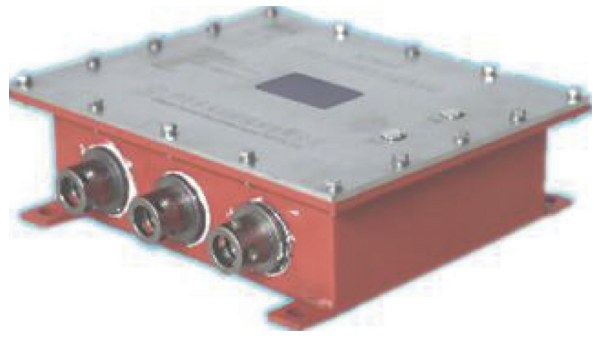

Figure 3: Roof pressure monitoring substation.

The monitoring stations of working face mining height, end-face distance, roof falling, rib spalling, and support pitch angle are arranged at one side of every 10 supports, a total of 17 monitoring stations.

\subsection{Analysis of Working Resistance Characteristics of Support.} The working resistance of 19 supports with $186 \mathrm{~m}$ advance and 233 coal cutting cycles in 103working face is statistically analyzed. Most of the working resistances of supports have shown obvious periodic change, as shown in Figure 5. Based on field observation and investigation, the following problems of multiple service supports are analyzed:

(1) It is shown in Figures 5(a) and 5(b) that the support is difficultly repaired and the right column of $49 \#$ support can work with high resistance continuously, but the left column only maintains high resistance performance for several coal cutting cycles although the left column of 49 \# support was repaired by a technician on $181 \mathrm{~m}, 200 \mathrm{~m}$, and $215 \mathrm{~m}$ and then shows continuous low resistance state. As a result, the working resistance does not reach the rated working resistance of the support, as shown in Figure 5(a).

(2) It is shown in Figure 5(d) that the left and right columns of 64\# support are still loaded unevenly although the columns keep pressure. The maximum pressure of the left column and the right column of $64 \#$ support is about $41 \mathrm{MPa}$ and $32 \mathrm{MPa}$, respectively. As a result, the working resistance does not reach the rated working resistance of the support, as shown in Figure 5(c).

(3) It is shown in Figures 5(a), 5(b), 5(e), and 5(f) that left or right columns of 49 \# and 118\# supports do not maintain pressure and the working resistance of the support is continuously low. As a result, the working resistance of the supports is only $6000-7000 \mathrm{kN}$ during periodic pressure.

(4) Based on the field observation, the roof subsidence is obvious, and the support safety valve is opened frequently. It can be inferred that the reason for the 


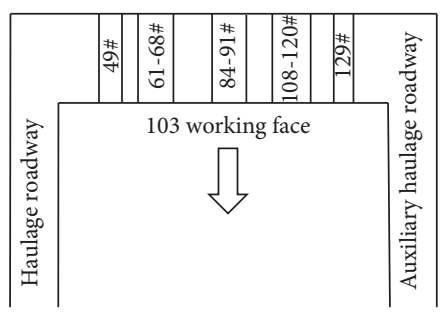

(a)

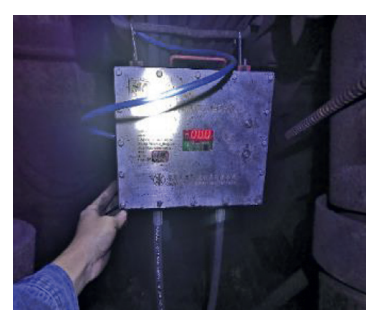

(b)

FIGURE 4: (a) Layout of monitoring stations for working resistance of support. (b) On-site monitoring.

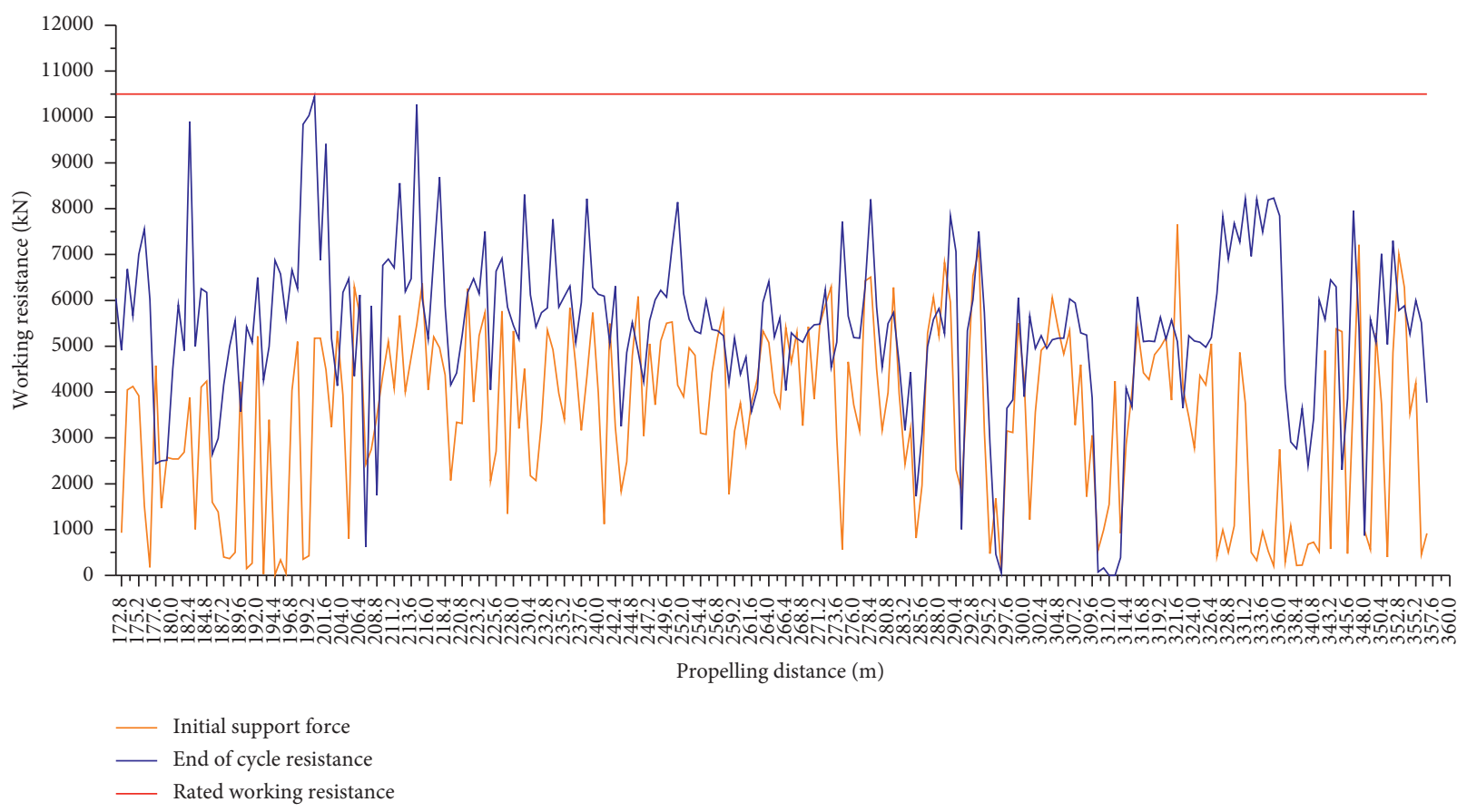

(a)

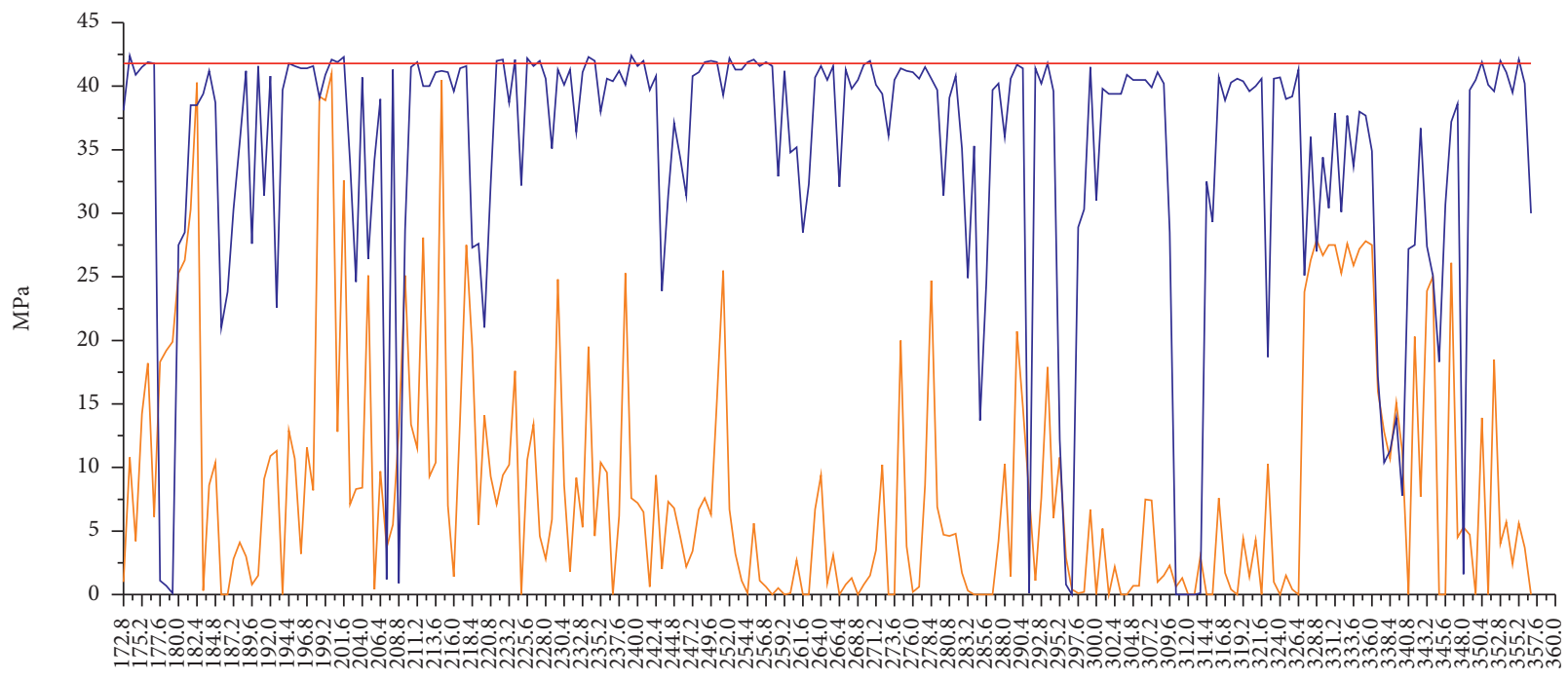

Propelling distance $(\mathrm{m})$

- End resistance of left column

_ End resistance of right column

- Opening pressure of safety value

(b)

Figure 5: Continued. 


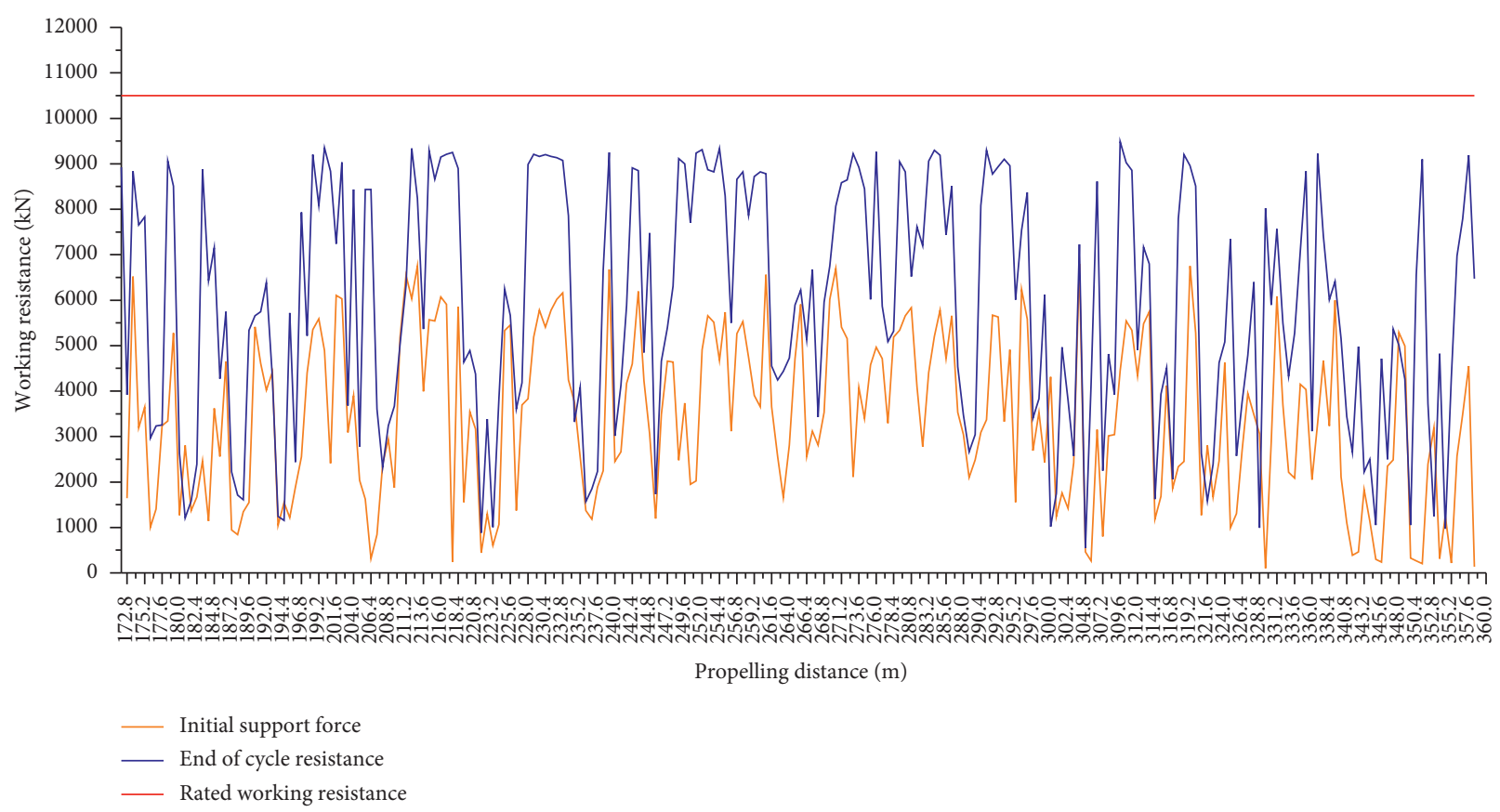

(c)

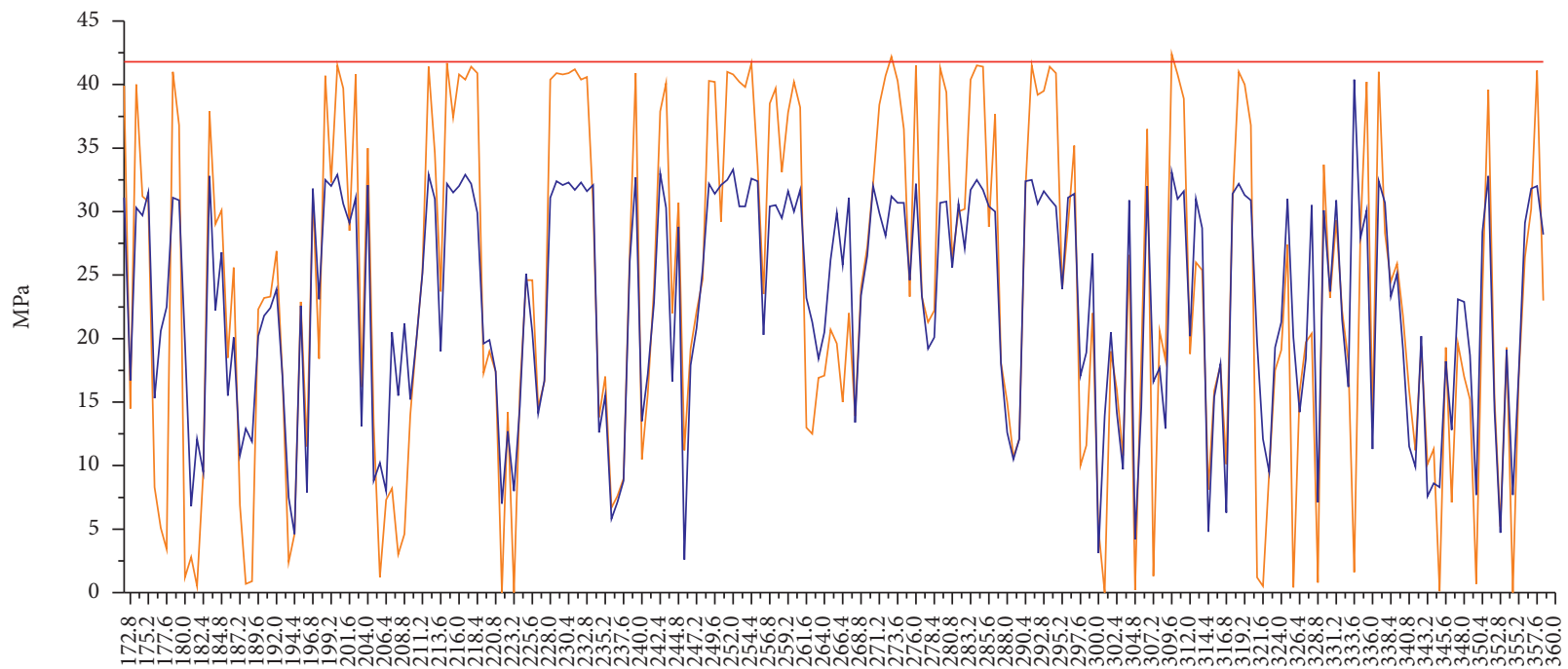

Propelling distance (m)

- End resistance of left column

__ End resistance of right column

__ Opening pressure of safety valve

(d)

FIgURe 5: Continued. 


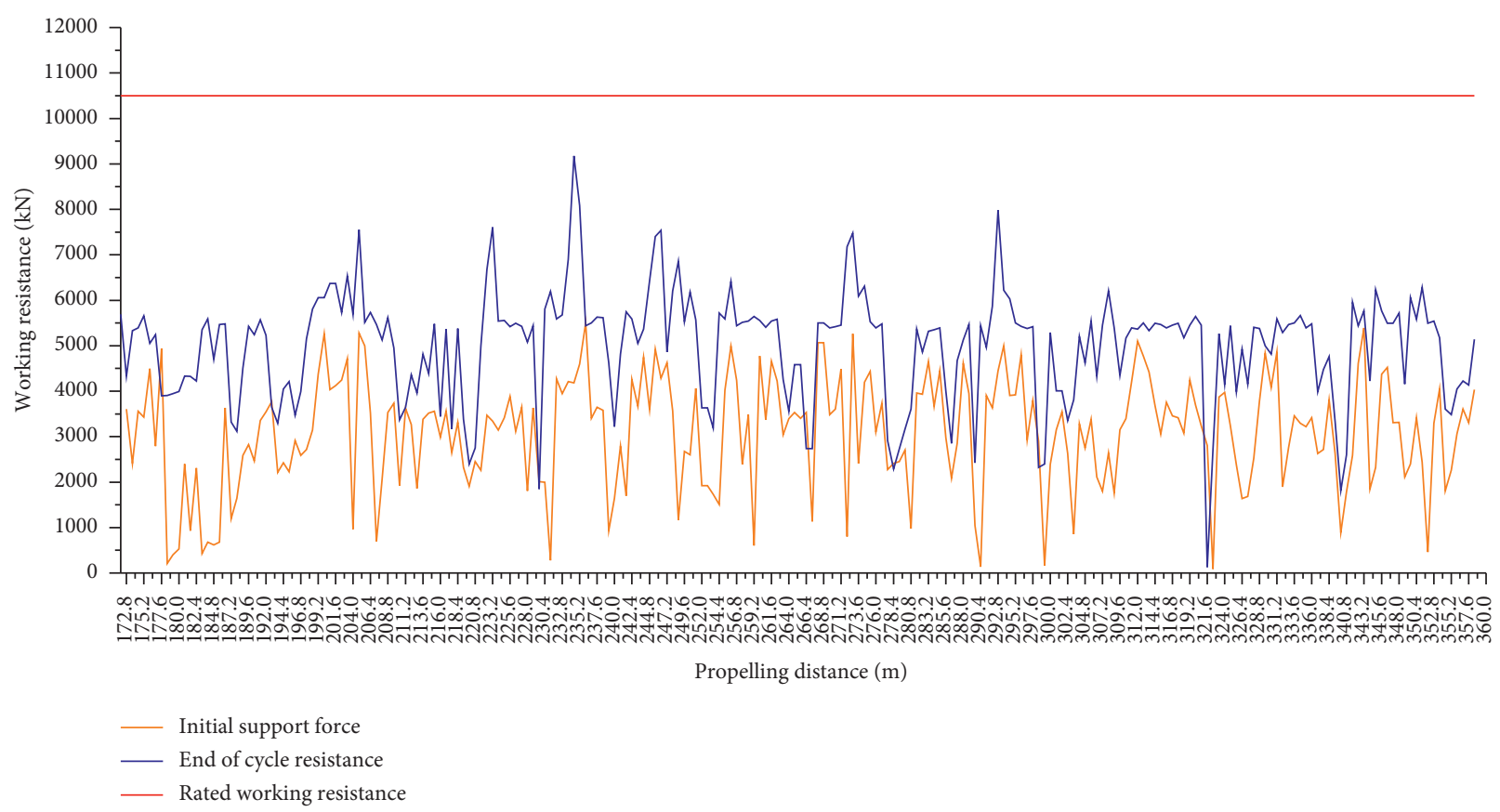

(e)

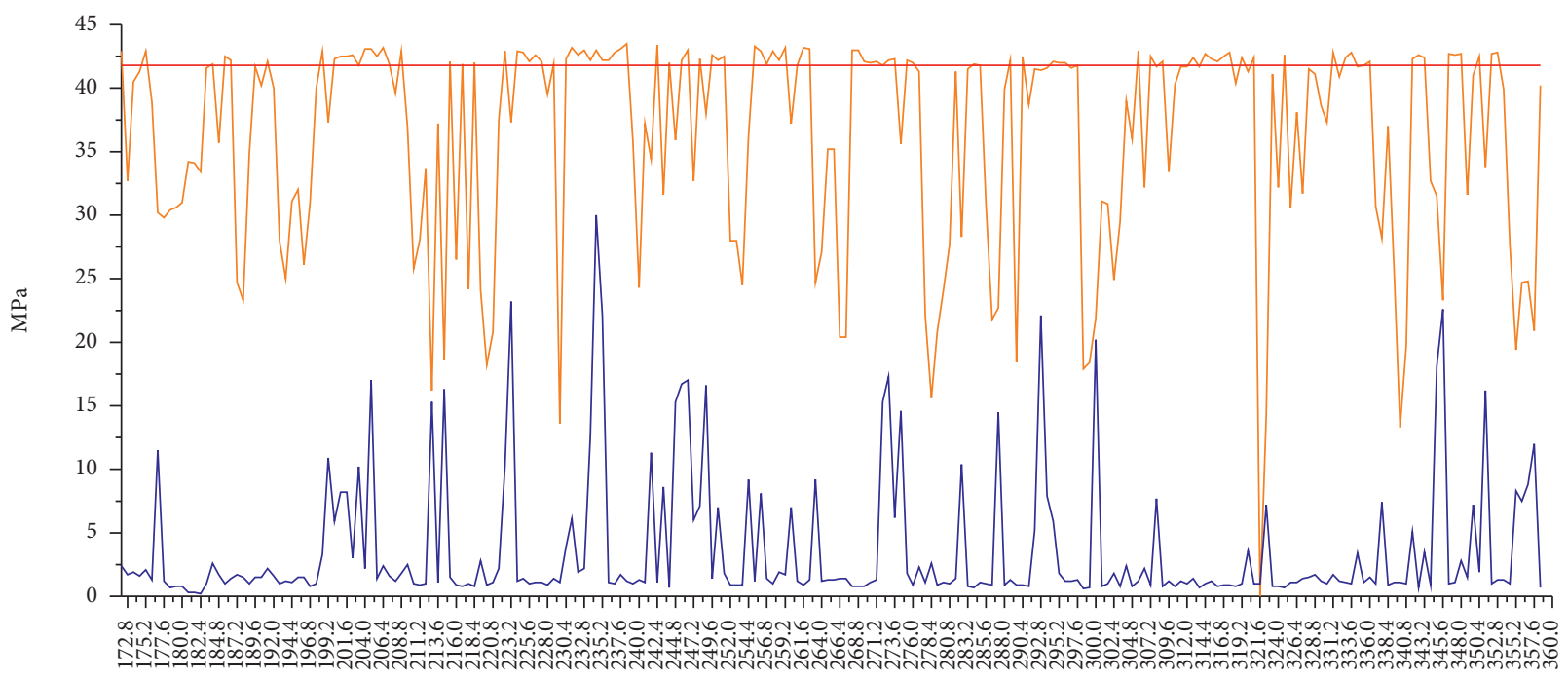

Propelling distance $(\mathrm{m})$

End resistance of left column

End resistance of right column

_ Opening pressure of safety valve

(f)

FIGURE 5: Circulation curve of working resistance of support and single column. (a) Circulation curve of working resistance of 49\# support. (b) Circulation curve of working resistance of a single column of 49\# support. (c) Circulation curve of working resistance of 64\# support. (d) Circulation curve of working resistance of a single column of 64\# support. (e) Circulation curve of working resistance of 118\# support. (f) Circulation curve of working resistance of a single column of $118 \#$ support.

low working resistance of some supports is not that the mine pressure is not intensive, but that the resistance performance of support is declined.

3.3. Actual Rated Working Resistance of Support. According to the real-time monitoring resistance of 64\# support, when the resistance of the support column does not reach the rated resistance, the safety valve is opened in advance. As shown in Figure 6, 64\# left and right columns of the support reach their peak pressures, respectively, and the real-time pressure fluctuates, showing signs of liquid leakage. Combined with Figures 6 and 5(d), the opening pressure of the safety valve of the left and right columns of 64\# support can be confirmed, that is, $40 \mathrm{MPa}$ and $32 \mathrm{MPa}$, respectively. The advance opening 


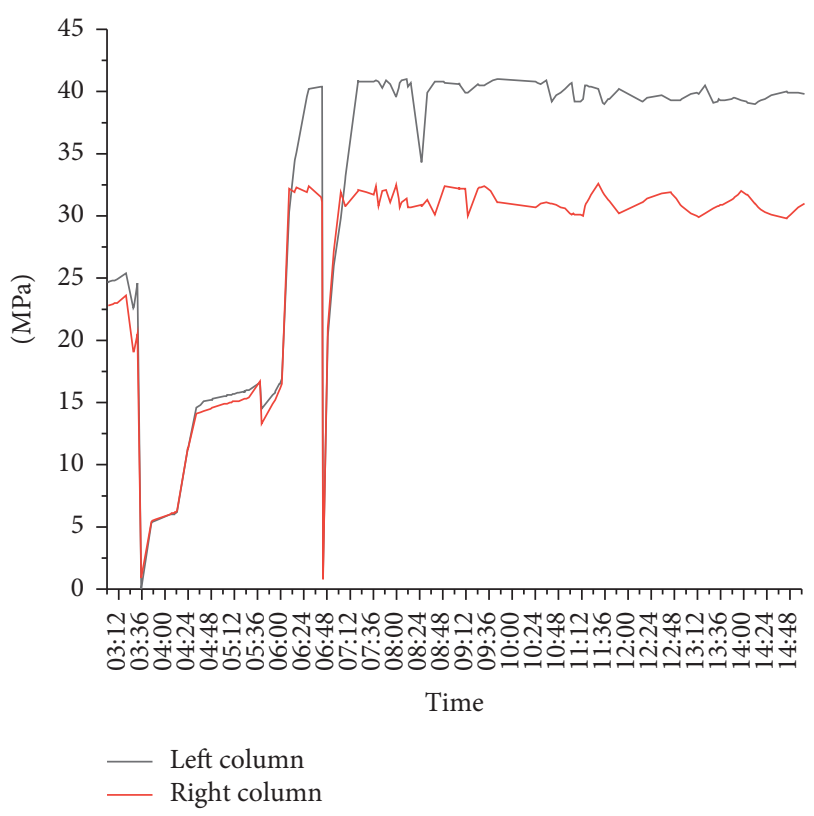

FIGURE 6: Real-time pressure history curve of 64\# support.

of the safety valve results in the decrease of the rated working resistance of the support. The maximum working resistance of the support can be calculated by the above method, which is defined as the actual rated working resistance of support $r_{i}(i$ is the support number).

The statistical results are shown in Table 1 . The "/" in Table 1 indicates that the resistance loss rate cannot be confirmed because the column does not maintain pressure. The average actual rated working resistance, $p^{\prime}=9300 \mathrm{kN}$, of the left and right columns maintaining the pressure of 14 supports can be calculated, which is about $12 \%$ lower than the rated working resistance.

3.4. Estimation of Actual Rated Resistance of All Supports in 103 Working Face. The actual rated working resistance of do not maintain pressure of 5 supports can be confirmed by the mean value of the resistance during periodic pressure of working face roof. It can be calculated by the following equation:

$$
P_{5}=\frac{p_{49}+p_{86}+p_{90}+p_{110}+p_{118}}{5}
$$

where $P_{5}$ is the actual rated working resistance of 5 supports (includes $49,86,90,110$, and 118\# support); $p_{i}(r=49,86,90$, 110 and 118) is the mean value of the resistance during periodic pressure of working face roof.

The actual rated working resistance of 5 supports is $P_{5}$ $6734 \mathrm{kN} . P_{19}$ is the actual rated working resistance of 19 supports of monitoring the mine pressure and can be calculated by the following equation:

$$
P_{19}=\frac{14 P^{\prime}+5 P_{5}}{19} \text {. }
$$

The actual rated working resistance of 19 supports is $P_{19}=8624 \mathrm{kN}$. It is about $18 \%$ lower than the rated working resistance. The resistance loss rate of unmonitored supports will be higher, so the actual rated working resistance of all supports, $P_{174}$, in 103 working face must be at least $18 \%$ lower than the rated working resistance.

The range of available monitoring supports is 49\#, 61 68\#, 84 91\#, 108 120\#, and 129\#, and 19 monitoring supports are selected from 31 supports. The maintaining pressure of 14 supports accounts for $45.16 \%$ of 31 supports. The actual rated working resistance of all supports in 103 working face can be calculated as follows:

$$
P_{174}=P^{\prime} \times 45.16 \% P_{5} 54.84 \% \text {, }
$$

where $P_{174}=7892.8 \sim 8624 \mathrm{kN}$. It is about $18 \sim 24.8 \%$ lower than the rated working resistance.

\section{Multifactor Evaluation of Support Performance}

4.1. Evaluation of Support Resistance Performance. The performance of the actual resistance of support can be reflected by the ratio of the mean resistance of support to the actual rated working resistance during periodic pressure. It is shown in Table 2 that as the resistance overrun rate of single support, 19 supports, and 174 supports is high during periodic pressure, the resistance performance of the support is insufficient. With the continuous advancement of the working face, the performance of supports will be further declined, and the mining of 105 working face needs to replace with new supports.

\subsection{Theoretical Calculation of Roof Subsidence and Roof Control Evaluation}

4.2.1. Calculation of the Total Amount of Roof Subsidence of Multiple Knife Coal Cutting under Periodic Pressure. The calculation of roof subsidence is based on the shrinkage of the support movable column. The shrinkage of the support movable column is the compression of the support movable column in the single cycle of coal cutting which can be calculated by the column length at the initial support minus the column length at the end support. The shrinkage of the support movable column is the result of basic roof rotation movement when roof compression and other factors are not considered, which is equal to the roof subsidence at the position of support column in the coal cutting cycle. During periodic pressure, the total amount of roof subsidence of multiple coal cutting cycles is related to the addition value of single cycle of roof subsidence. If the roof pressure is greater than the actual rated working resistance of the support, the shrinkage of the movable column of support will be increased continuously in each coal cutting cycle. During the roof periodic pressure, the distance between the support column and the basic roof fracture line is continuously reduced with the advancement of the working face and the support is moved forward. When the accumulated roof subsidence of the working face in the early stage of periodic pressure is converted to the accumulated roof subsidence of the 
TABLE 1: Actual rated working resistance of the support.

\begin{tabular}{|c|c|c|c|c|c|c|}
\hline $\begin{array}{l}\text { Support } \\
\text { number }\end{array}$ & $\begin{array}{l}\text { Left column } \\
\qquad(\mathrm{MPa})\end{array}$ & $\begin{array}{l}\text { Resistance loss rate of } \\
\text { the left column (\%) }\end{array}$ & $\begin{array}{l}\text { Right } \\
\text { column } \\
(\mathrm{MPa})\end{array}$ & $\begin{array}{l}\text { Resistance loss rate of } \\
\text { the right column (\%) }\end{array}$ & $\begin{array}{l}\text { Actual rated working } \\
\text { resistance of the support } \\
r_{i}(\mathrm{kN})\end{array}$ & $\begin{array}{l}\text { Resistance loss rate } \\
\text { of the support (\%) }\end{array}$ \\
\hline 49 & 1 & 1 & 39 & 7 & 1 & 1 \\
\hline 61 & 26 & 38 & 37 & 11 & 7917 & 25 \\
\hline 62 & 40 & 4 & 41 & 2 & 10178 & 3 \\
\hline 64 & 41 & 2 & 32 & 23 & 9173 & 13 \\
\hline 67 & 39 & 7 & 32 & 23 & 8922 & 15 \\
\hline 68 & 38 & 9 & 39.5 & 6 & 9739 & 8 \\
\hline 84 & 33 & 21 & 36 & 14 & 8671 & 18 \\
\hline 85 & 38 & 9 & I & 1 & I & 1 \\
\hline 86 & 40 & 4 & 1 & I & I & I \\
\hline 88 & 35 & 16 & 38 & 9 & 9173 & 13 \\
\hline 89 & 39 & 7 & 39 & 7 & 9801 & 7 \\
\hline 90 & 34 & 19 & I & I & I & I \\
\hline 91 & 40 & 4 & 36 & 14 & 9550 & 9 \\
\hline 108 & 41 & 2 & 40 & 4 & 10178 & 3 \\
\hline 110 & I & I & 28 & 33 & 1 & I \\
\hline 111 & 38 & 9 & 40 & 4 & 9801 & 7 \\
\hline 118 & 41 & 2 & 1 & 1 & 1 & 1 \\
\hline 120 & 39 & 7 & 33 & 21 & 9048 & 14 \\
\hline 129 & 38 & 9 & 36 & 14 & 9299 & 11 \\
\hline Average & 37.6 & 10 & 37 & 11.3 & $p^{\prime}=9300$ & 12 \\
\hline
\end{tabular}

TABLE 2: The overrun rate of supports working resistance during periodic pressure.

\begin{tabular}{lccccc}
\hline $\begin{array}{l}\text { Support } \\
\text { number }\end{array}$ & $\begin{array}{c}p_{i}(\mathrm{kN})(i \text { is the } \\
\text { support number })\end{array}$ & $\begin{array}{c}\text { Mean square } \\
\text { deviation }(\mathrm{kN})\end{array}$ & $\begin{array}{c}p_{i} / r_{i}(\%)(i \text { is the } \\
\text { support number })\end{array}$ & $\begin{array}{c}p_{i} / P_{19}(\%)(i \text { is the } \\
\text { support number })\end{array}$ & $\begin{array}{c}p_{i} / P_{174}(\%)(i \text { is the support } \\
\text { number })\end{array}$ \\
\hline $49 \#$ & 7024.75 & 1565.27 & 100 & 81.40 & $81.40 \sim 89.00$ \\
$61 \#$ & 7471 & 1656.76 & 94.37 & 86.70 & 117.05 \\
$62 \#$ & 10094.7 & 631.15 & 99.17 & 104.05 & $117.05 \sim 127.90$ \\
$64 \#$ & 8972.90 & 882.82 & 97.81 & 102.74 & $104.05 \sim 113.68$ \\
$67 \#$ & 8859.67 & 825.4 & 99.31 & 112.4 & $102.74 \sim 112.25$ \\
$68 \#$ & 9693.33 & 990.09 & 99.53 & 86.69 & $112.4 \sim 122.81$ \\
$84 \#$ & 7477.00 & 1290.32 & 86.23 & 104.85 & $86.69 \sim 94.73$ \\
$85 \#$ & 9042.54 & 975.3 & 100 & 91.64 & $104.85 \sim 114.57$ \\
$86 \#$ & 7903.10 & 1133.82 & 100 & 98.63 & $91.64 \sim 100.13$ \\
$88 \#$ & 8506 & 989.08 & 92.73 & 111.22 & $98.63 \sim 107.77$ \\
$89 \#$ & 9592 & 867.09 & 97.87 & 107.74 & $111.22 \sim 121.53$ \\
$91 \#$ & 9291.69 & 957 & 97.29 & 96.43 & $107.74 \sim 117.72$ \\
$108 \#$ & 9955 & 912.7 & 97.81 & 96.73 & $115.43 \sim 126.13$ \\
$111 \#$ & 8342 & 1359.78 & 85.11 & 75.48 & $96.73 \sim 105.69$ \\
$118 \#$ & 6509 & 2315 & 100 & 104.33 & $75.48 \sim 82.47$ \\
$120 \#$ & 8997 & 1374.65 & 99.44 & 104.76 & $104.33 \sim 113.99$ \\
$129 \#$ & 9034.4 & 1117.15 & 97.15 & 100.79 & $104.76 \sim 114.46$ \\
Average & 8692 & 1167 & 96.70 & $100.79 \sim 110.13$ \\
\hline
\end{tabular}

current coal cutting cycle, it will be reduced. The roof subsidence of each coal cutting cycle in the whole roof periodic pressure should be monitored to be converted it into cumulative roof subsidence. It is defined that there are $n$ coal cutting cycles in the roof periodic pressure, and the shrinkage of the movable column (roof subsidence) in each coal cutting cycle is $h_{i}$. When the periodic pressure comes to end, the distance between the support column and the basic roof fracture line is $\lambda$ times of the single coal cutting distance.

The conversion coefficient of $i$ coal cutting cycle to the roof subsidence of $j$ coal cutting cycle is $k_{i j},(j>i)$, and it can be calculated as follows:

$$
k_{i j}=\frac{n-j+\lambda}{j-i+\lambda} .
$$

The conversion value of $i$ coal cutting cycle to the roof subsidence of $j$ coal cutting cycle is $h_{i j}$, and it can be calculated by the following equation:

$$
h_{i j}=h_{i} k_{i j}=h_{i} \frac{n-j+\lambda}{n-i+\lambda} .
$$

At the end of $j$ coal cutting cycle, the accumulated subsidence of the roof is $h_{j m}$, and it can be calculated by equation (6) As shown in Figure 7, 


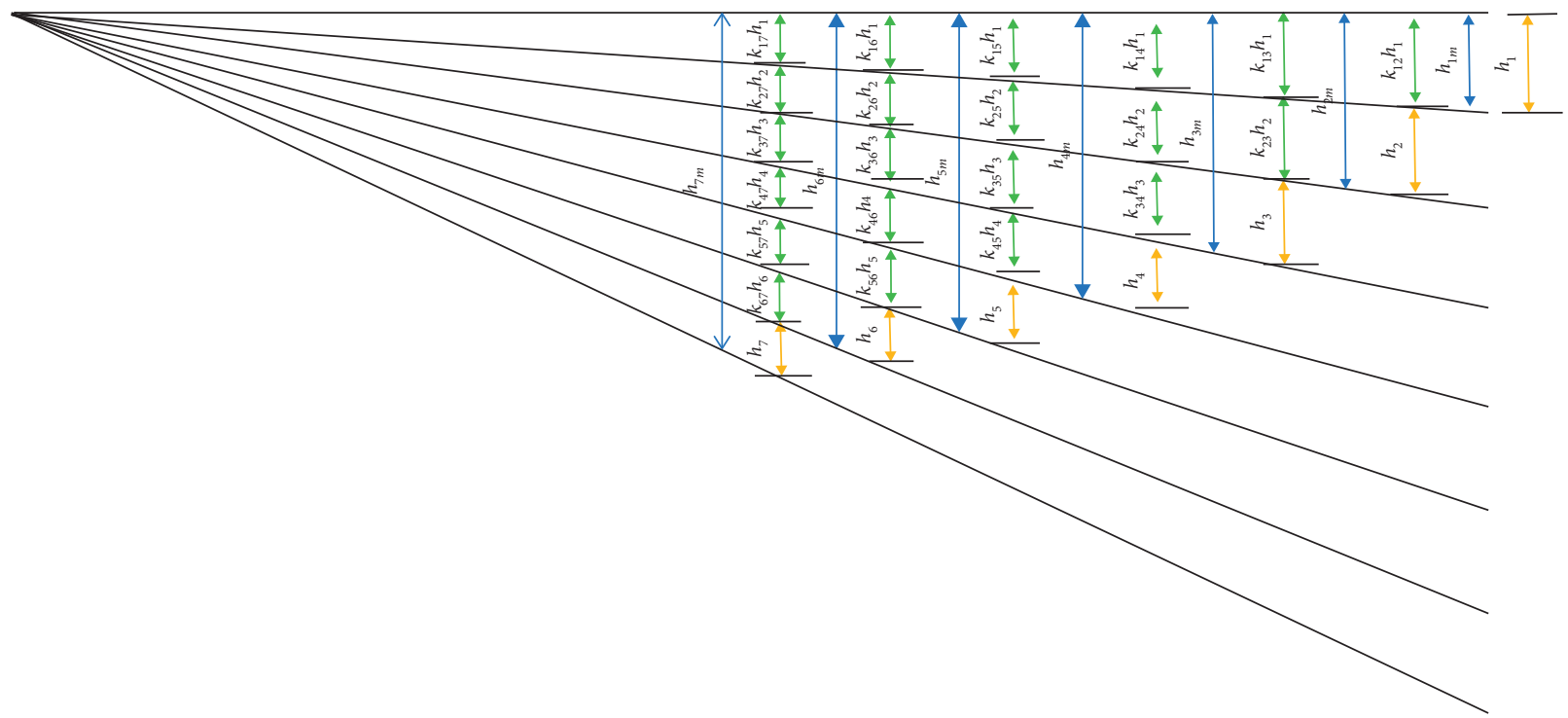

FIgURE 7: Calculation diagram of total roof subsidence during periodic pressure.

$$
\begin{aligned}
h_{j m}= & h_{1} \frac{n-j+\lambda}{n-1+\lambda}+h_{2} \frac{n-j+\lambda}{n-2+\lambda}+h_{3} \frac{n-j+\lambda}{n-3+\lambda}+\cdots \\
& +h_{j-1} \frac{n-j+\lambda}{n-j+1+\lambda}+h_{j} .
\end{aligned}
$$

Six key supports $(62 \#, 64 \#, 67 \#, 89 \#, 108 \#$, and 120\#) are analyzed emphatically, which refer to 3 supports with the maximum working resistance close to the rated working resistance $(10500 \mathrm{kN})$ and 3 supports with the maximum working resistance close to the actual rated working resistance $(9300 \mathrm{kN})$ of 14 maintaining pressure supports. It is calculated that the average roof subsidence of each knife coal cutting of the 6 key support positions is $65 \mathrm{~mm}$. From the analysis of pressure data, it can be seen that $j=7, \lambda=4$, and $h_{7 m}$ can be calculated as $283 \mathrm{~mm}$ by equation (6).

4.2.2. Evaluation of Roof Control Effect. The roof control effect standard of 103 working face is shown in Table 3.

The effect level of roof controlled is "medium," so the level of roof control needs to be improved. If the multiple service supports continue to be used in the 105 working face, the effect of roof control is still "medium" or even "poor." It is necessary to replace the new supports to improve the level of roof control in the 105 working face.

4.3. Evaluation of Support System Performance of Supports by $F A H P+E W M$. Because the support system performance of support is affected by many mine fuzzy factors, it is necessary to quantify the fuzzy factors and get the quantitative evaluation value. FAHP and EWM are, respectively, fuzzy analytic hierarchy process and entropy weight method [35-38], which can be used to evaluate the performance of the support system and get quantitative value.
4.3.1. Establishing Factor Set. Factor set A is shown in Figure 8.

4.3.2. Calculation of Index Factor. For the evaluation of support performance, triangle fuzzy number is introduced, and the fuzzy set on the index domain is given. $\mu(x)(\mu(x) \in[0,1])$ which can be corresponded to $X$ is the membership degree of $X$, and it can be expressed as follows:

$$
\mu(x)=\left\{\begin{array}{c}
0, x<x_{1} \\
\frac{x-x_{1}}{x_{0}-x_{1}}, \quad x \in\left[x_{1}, x_{0}\right] \\
\frac{x_{2}-x}{x_{2}-x_{0}}, \quad x \in\left[x_{0}, x_{2}\right] \\
0, x>x_{2}
\end{array}\right\} .
$$

4.3.3. Construction of Judgment Matrix. The effect of the lower level elements on the upper level elements is confirmed, that is, the weight value. The importance of factor $B_{i}$ to factor $B_{j}$ can be represented by $b_{i j}$, as is shown in Figure 9.

4.3.4. Weight Calculation and Consistency Test. The weight value of each index and the consistency of the judgment matrix can be calculated and checked by equations (8)-(12).

(1) The judgment matrix can be normalized as follows:

$$
\overline{b_{i j}}=\frac{b_{i j}}{\sum_{i=1}^{n} b_{i j}}, \quad i=1,2,3, \ldots, n,
$$


TABLE 3: Roof control effect standard of 103 working face.

\begin{tabular}{lcccc}
\hline Number & 1 & 2 & 3 & 4 \\
\hline Roof control effect standard & Excellent & Good & Medium & Poor \\
Roof subsidence $\Delta h_{i}(\mathrm{~mm})$ & $0 \sim 150$ & $151 \sim 250$ & $251 \sim 400$ & $>400$ \\
\hline
\end{tabular}

\begin{tabular}{|c|c|c|c|}
\hline \multicolumn{4}{|c|}{$A$ target layer } \\
\hline \begin{tabular}{|c}
$B_{1}$ personnel \\
factor
\end{tabular} & $\begin{array}{c}B_{2} \text { equipment } \\
\text { factor }\end{array}$ & \begin{tabular}{|c|}
$B_{3}$ geological \\
factors
\end{tabular} & $\begin{array}{c}B_{4} \text { management } \\
\text { factor }\end{array}$ \\
\hline $\begin{array}{c}C_{1} \text { quality of } \\
\text { personnel } \\
C_{2} \text { technician } \\
\text { training } \\
C_{3} \text { safety } \\
\text { consciousness } \\
C_{4} \text { the average } \\
\text { length of } \\
\text { service }\end{array}$ & \begin{tabular}{|c|}
$C_{5}$ value leakage \\
$C_{6}$ column \\
failure \\
$C_{7}$ irregular \\
moving support \\
$C_{8}$ resistance \\
loss rate \\
$C_{9}$ support part \\
failure \\
$C_{10}$ pitch angle \\
of support \\
$C_{11}$ initial \\
supporting \\
failure
\end{tabular} & $\begin{array}{c}C_{12} \text { coal seam } \\
\text { dip angle } \\
C_{13} \text { coal } \\
\text { hardness } \\
C_{14} \text { geological } \\
\text { structure } \\
C_{15} \text { buried } \\
\text { depth of coal } \\
\text { seam } \\
C_{16} \text { rock burst } \\
\text { tendency } \\
C_{17} \text { direct roof } \\
\text { thickness } \\
C_{18} \text { mining } \\
\text { height }\end{array}$ & $\begin{array}{c}C_{19} \text { safety } \\
\text { production } \\
\text { responsibility } \\
C_{20} \text { accident } \\
\text { prevention and } \\
\text { treatment } \\
C_{21} \text { reward and } \\
\text { punishment } \\
\text { policy } \\
C_{22} \text { safety } \\
\text { inspection } \\
\text { system } \\
C_{23} \text { safety } \\
\text { input }\end{array}$ \\
\hline
\end{tabular}

Figure 8: Factor set A.

\begin{tabular}{c|ccccc}
$A$ & $B_{1}$ & $B_{2}$ & $B_{3}$ & $\ldots$ & $B_{n}$ \\
\hline$B_{1}$ & $b_{11}$ & $b_{12}$ & $b_{13}$ & $\ldots$ & $b_{1 n}$ \\
$B_{2}$ & $b_{21}$ & $b_{22}$ & $b_{23}$ & $\ldots$ & $b_{2 n}$ \\
$B_{3}$ & $b_{31}$ & $b_{32}$ & $b_{33}$ & $\ldots$ & $b_{3 n}$ \\
$\vdots$ & $\vdots$ & $\vdots$ & $\vdots$ & $\ddots$ & $\ldots$ \\
$B_{n}$ & $b_{n 1}$ & $b_{n 2}$ & $b_{n 3}$ & $\ldots$ & $b_{n n}$
\end{tabular}

FIgURE 9: Diagram of the judgment matrix.

where $\bar{b}_{i j}$ is the elements of the normalized judgment matrix.

(2) The eigenvector of the normalized judgment matrix can be calculated by the following equation:

$$
\overline{w_{i}}=\sum_{j=1}^{n} \overline{b_{i j}}, \quad j=1,2,3, \ldots, n,
$$

where $\bar{w}_{i}$ is the eigenvector of the normalized judgment matrix.

(3) The relative weight vector can be calculated by the following equation:

$$
\bar{W}_{i}=\frac{\bar{w}_{i}}{\sum_{i=1}^{n} \bar{w}_{i}}, \quad i=1,2,3 \ldots n
$$

where $\bar{w}_{i}$ is the relative weight vector.

(4) The eigenvalues of the normalized judgment matrix can be calculated by equation (11). The consistency index of the judgment matrix can be checked by equation (12):

$$
\begin{aligned}
\lambda_{\max } & =\frac{1}{n} \sum_{i=1}^{n} \frac{(A \bar{W})_{i}}{\overline{W_{i}}}, \\
\mathrm{CI} & =\frac{\lambda_{\max }-n}{n-1},
\end{aligned}
$$

where $\lambda_{\max }$ is eigenvalues of the normalized judgment matrix, $A$ is the judgment matrix, $\mathrm{CI}$ is the consistency index of the judgment matrix, and $n$ is the order of the judgment matrix.

4.3.5. EWM Is Used to Modify Weight Value to Get Combination Weight Value. According to the theory of information entropy, the weight value of the index factor is modified, and information entropy can be simply written by the following equation:

$$
\begin{gathered}
S=-p \ln p, \\
p=\frac{f_{i}}{\sum_{i=1}^{n} f_{i}}
\end{gathered}
$$

where $S$ is the information entropy, $p$ is the index factor coefficient, and $f_{i}$ is the index factor membership value.

The relative entropy weight value of the index factor can be calculated by the following equation:

$$
W_{i}=\frac{D_{i j}}{\sum_{j=1}^{n} D_{i j}}
$$

where $D_{i j}$ is the entropy weight value and $W_{i}$ is the relative entropy weight value.

The combination weight value can be calculated by the following equation:

$$
\omega=\frac{[\bar{W}, t W]}{\sum[\bar{W}, t W]}
$$

where $\omega$ is the combination weight value.

4.3.6. Comprehensive Evaluation Results. Various parameters of index factors are shown in Table 4, and it can be quantified by the following equation to clearly show the support system performance of multiple service supports:

$$
F=100 \sum_{i=1}^{4} \omega_{i} \sum_{j=1}^{23} \omega_{i} f_{j}
$$


TABLE 4: Various parameters of index factors.

\begin{tabular}{|c|c|c|c|c|c|}
\hline $\begin{array}{l}\text { Primary index } \\
\text { factor }\end{array}$ & $\begin{array}{c}\text { Combination weight } \\
\text { value } \omega_{i}\end{array}$ & Secondary index factor & $\begin{array}{c}\text { Combination weight } \\
\text { value } \omega_{i j}\end{array}$ & $\begin{array}{l}\text { Index factor membership } \\
\text { value } f_{j}\end{array}$ & $\omega_{i j} * f_{j}$ \\
\hline \multirow{4}{*}{$B_{1}$ personnel factor } & \multirow{4}{*}{0.0528} & $C_{1}$ quality of personnel & 0.265 & 0.833 & 0.221 \\
\hline & & $C_{2}$ technician training & 0.140 & 1 & 0.140 \\
\hline & & $C_{3}$ safety consciousness & 0.088 & 0.8 & 0.070 \\
\hline & & $C_{4}$ average length of service & 0.507 & 0.843 & 0.427 \\
\hline \multirow{7}{*}{$\begin{array}{l}B_{2} \text { equipment } \\
\text { factor }\end{array}$} & \multirow{7}{*}{0.4736} & $C_{5}$ valve leakage & 0.038 & 0.4 & 0.015 \\
\hline & & $C_{6}$ column failure & 0.199 & 0.28 & 0.056 \\
\hline & & $C_{7}$ irregular moving support & 0.186 & 0.503 & 0.093 \\
\hline & & $C_{8}$ resistance loss rate & 0.160 & 0.4 & 0.064 \\
\hline & & $C_{9}$ support part failure & 0.047 & 0.58 & 0.027 \\
\hline & & $C_{10}$ pitch angle of support & 0.080 & 0.763 & 0.061 \\
\hline & & $C_{11}$ initial supporting force & 0.290 & 0.028 & 0.008 \\
\hline \multirow{7}{*}{$\begin{array}{l}B_{3} \text { geological } \\
\text { factors }\end{array}$} & \multirow{7}{*}{0.2263} & $C_{12}$ coal seam dip angle & 0.056 & 1 & 0.056 \\
\hline & & $C_{13}$ coal hardness & 0.086 & 0.6 & 0.051 \\
\hline & & $C_{14}$ geological structure & 0.227 & 1 & 0.227 \\
\hline & & $C_{15}$ buried depth of coal seam & 0.071 & 1 & 0.071 \\
\hline & & $C_{16}$ rock burst tendency & 0.214 & 1 & 0.214 \\
\hline & & $C_{17}$ direct roof thickness & 0.130 & 0.25 & 0.032 \\
\hline & & $C_{18}$ mining height & 0.216 & 0.8 & 0.173 \\
\hline \multirow{5}{*}{$\begin{array}{l}B_{4} \text { management } \\
\text { factor }\end{array}$} & \multirow{5}{*}{0.2473} & $\begin{array}{l}C_{19} \text { safety production } \\
\text { responsibility }\end{array}$ & 0.417 & 1 & 0.417 \\
\hline & & $\begin{array}{c}C_{20} \text { accident prevention and } \\
\text { treatment }\end{array}$ & 0.060 & 1 & 0.060 \\
\hline & & $\begin{array}{c}C_{21} \text { reward and punishment } \\
\text { policy }\end{array}$ & 0.125 & 1 & 0.125 \\
\hline & & $C_{22}$ safety inspection system & 0.125 & 1 & 0.125 \\
\hline & & $C_{23}$ safety input & 0.273 & 1 & 0.273 \\
\hline
\end{tabular}

TABLE 5: Grade parameter vector corresponding grade score.

\begin{tabular}{lcccc}
\hline Grade & $\begin{array}{c}\text { Grade } \\
\text { interval }\end{array}$ & Comment & $\begin{array}{c}\text { Parameter } \\
\text { vector }\end{array}$ & $\begin{array}{c}\text { Grade } \\
\text { score }\end{array}$ \\
\hline I & $90 \sim 100$ & Excellent & 90 & 0.9 \\
II & $80 \sim 90$ & Good & 80 & 0.8 \\
III & $60 \sim 80$ & General & 60 & 0.6 \\
IV & $40 \sim 60$ & Poor & 40 & 0.4 \\
V & $10 \sim 40$ & Extremely & 10 & 0.1 \\
\hline
\end{tabular}

where $F$ is the evaluation value of support system performance of multiple service supports and $F=63.31$

It is shown in Table 5 that fuzzy evaluation is divided into 5 grades. The support system performance of multiple service supports is evaluated as "general" and is close to "poor." As the leading factor of overall performance evaluation, the evaluation score of the equipment factor criterion layer will be continued to decline with the continuous mining of 103 working face. As a result, the support system performance level will be reduced to "poor" or even "extremely poor," so it is necessary to replace the new supports to improve the level of the support system performance in 105 working face.

\section{Optimization of Reasonable Working Resistance of Support}

The new method is used for determining the reasonable working resistance of support based on the measured pressure data of dynamic pressure. According to the statistics of the end resistance of support in sufficient coal cutting cycle of 103 working face, 5 kinds of working resistances of support during periodic pressure are obtained, and they include the rated working resistance of support, the actual rated working resistance of support, the mean resistance of support under periodic pressure, the mean partial resistance of support, and the mean upper resistance of support. According to the potential state equation [12], the roof subsidence under different working resistances can be calculated by the potential state equation, and the reasonable working resistance of support in 103 working face can be determined. Using the new method to determine the reasonable working resistance of support, it is necessary to ensure that the effect of roof control of the working face cannot be poor under the condition of using the existing support. The measured mine pressure in the working face must be a true reflection that the resistance of the support can resist the roof pressure of the working face. The roof control effect of 103 working face is "medium," and the measured mine pressure can reflect the real roof pressure, so this method can be used to select the support of 103 working face.

5.1. Obtaining 5 Kinds of Working Resistances of Support. 6 key supports are described in Section 4.2.1.

(1) The rated working resistance of support is $p=10500 \mathrm{kN}$. The variance $\sigma_{n}$ is $915 \mathrm{kN}$. 


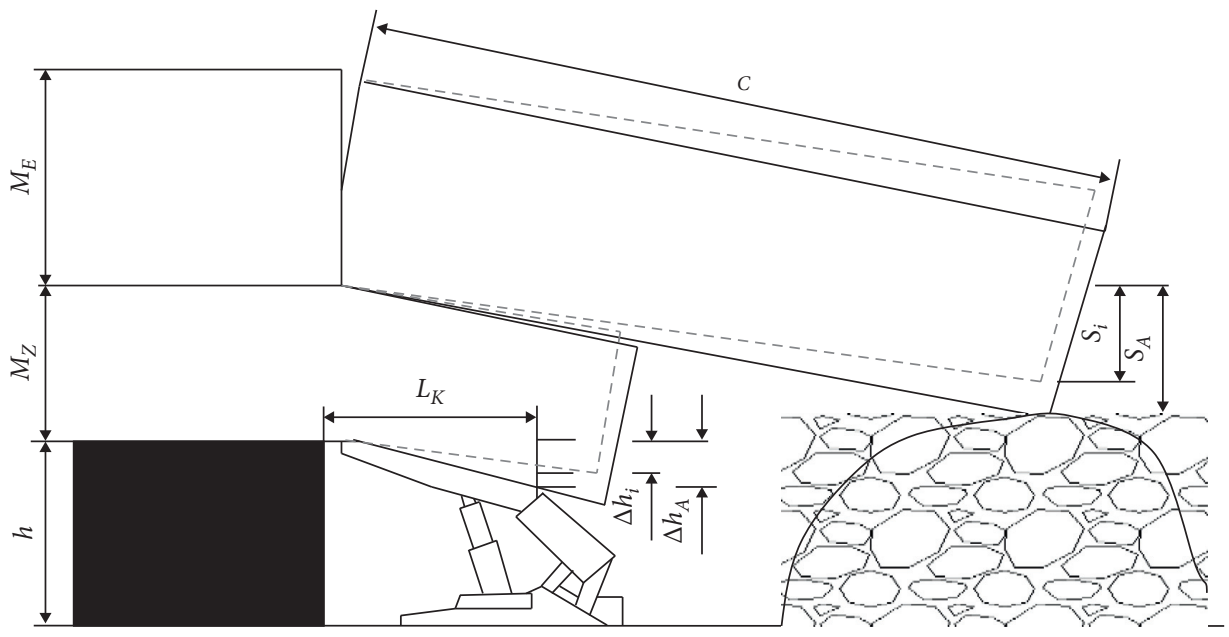

Figure 10: Schematic diagram of the roof control position in the mining face.

TABLE 6: The roof control level corresponding to 5 working resistances of support.

\begin{tabular}{lccccc}
\hline Resistance of support $(\mathrm{kN})$ & $p=10500$ & $p^{\prime}=9300$ & $\bar{p}=9412$ & $\bar{p}_{1}=10327$ & $\bar{p}_{2}=12157$ \\
\hline Roof subsidence $\Delta h_{i}(\mathrm{~mm})$ & $\Delta h_{1}=219$ & $\Delta h_{2}=290$ & $\Delta h_{3}=283$ & $\Delta h_{4}=227$ & $\Delta h_{5}=163$ \\
Roof control effect & Good & Medium & Medium & Good & Good \\
\hline
\end{tabular}

(2) As described in Section 3.3, the actual rated working resistance of support is $p^{\prime}=9300 \mathrm{kN}$.

(3) The mean resistance of 6 key supports under periodic pressure is $\bar{p}=9412 \mathrm{kN}$.

(4) The mean partial resistance of 6 key supports can be calculated as follows:

$$
\overline{p_{1}}=\bar{p}+\sigma_{n}=10327 \mathrm{kN} \text {, }
$$

where $\bar{p}_{1}$ is the mean partial resistance of 6 key supports; $\sigma_{n}$ is the variance.

(5) The mean upper resistance of 6 key supports can be calculated as follows:

$$
\overline{p_{2}}=\bar{p}+3 \sigma_{n}=12157 \mathrm{kN}
$$

where $\bar{p}_{2}$ is the mean upper resistance of 6 key supports.

\subsection{Checking the Reasonable Resistance of Support in 103 Working Face}

5.2.1. Calculation of Roof Subsidence under Different Working Resistances of Support. The roof subsidence of the working face can be quantitatively calculated by equation (20), according to the condition of limited deformation of support. The roof control position of the working face is shown in Figure 10 [12]:where $p_{0}$ is the mean working resistance of support before periodic pressure, $5663 \mathrm{kN}$, and $k$ is the roof state constant, $\mathrm{kN}$.

$$
\bar{p}=p_{0}+k \frac{\Delta h_{A}}{\Delta h_{i}}
$$

Roof subsidence corresponding to the 5 resistances of support is $p-\Delta h_{1}, p^{\prime}-\Delta h_{2}, \bar{p}-\Delta h_{3}, \bar{p}_{1}-\Delta h_{4}$, and $\bar{p}_{2}-\Delta h_{5}$, respectively.

When the basic roof is at the lowest position, the roof subsidence at the position of support column is $\Delta h_{A}$, and it can be calculated as follows:

$$
\Delta h_{A}=\frac{h-M_{z}\left(K_{A}-1\right)}{c} \cdot L_{K}
$$

where $h$ is the mining height, $4.0 \mathrm{~m} ; M_{z}$ is the direct roof thickness, $6.0 \mathrm{~m}$; $c$ is the periodic pressure step, $15 \mathrm{~m} ; K_{A}$ is the coefficient of direct roof crushing expansion, 1.3; and $L_{K}$ is the average control distance of support column, $4.239 \mathrm{~m}$.

As described in Section 5.1.1, the roof subsidence corresponding to the 5 resistances of support can be calculated by equations (20) and (21). The roof control level corresponding to 5 working resistances of support is shown in Table 6.

\subsubsection{Overrun Ratio of End Resistance of Support at Periodic} Pressure. The diagram of 5 kinds of working resistances of 6 key supports in 103 working face is shown in Figure 11. 5 kinds of working resistances are described in Section 5.1.1 and $r$ is the curve of end resistance of support of coal cutting cycle.

The ratio of the end resistance of 6 key supports of coal cutting cycle to exceed $p, p^{\prime}, \bar{p}, \bar{p}_{1}$, and $\bar{p}_{2}$ is shown in Table 7 . There are two statistical methods: one is the ratio $A_{1}$ of the over limit value to the total cycles in advancing $180 \mathrm{~m}$, and the other is the ratio $A_{2}$ of the over limit value to the cycles of 12-14 periodic pressure in advance. 


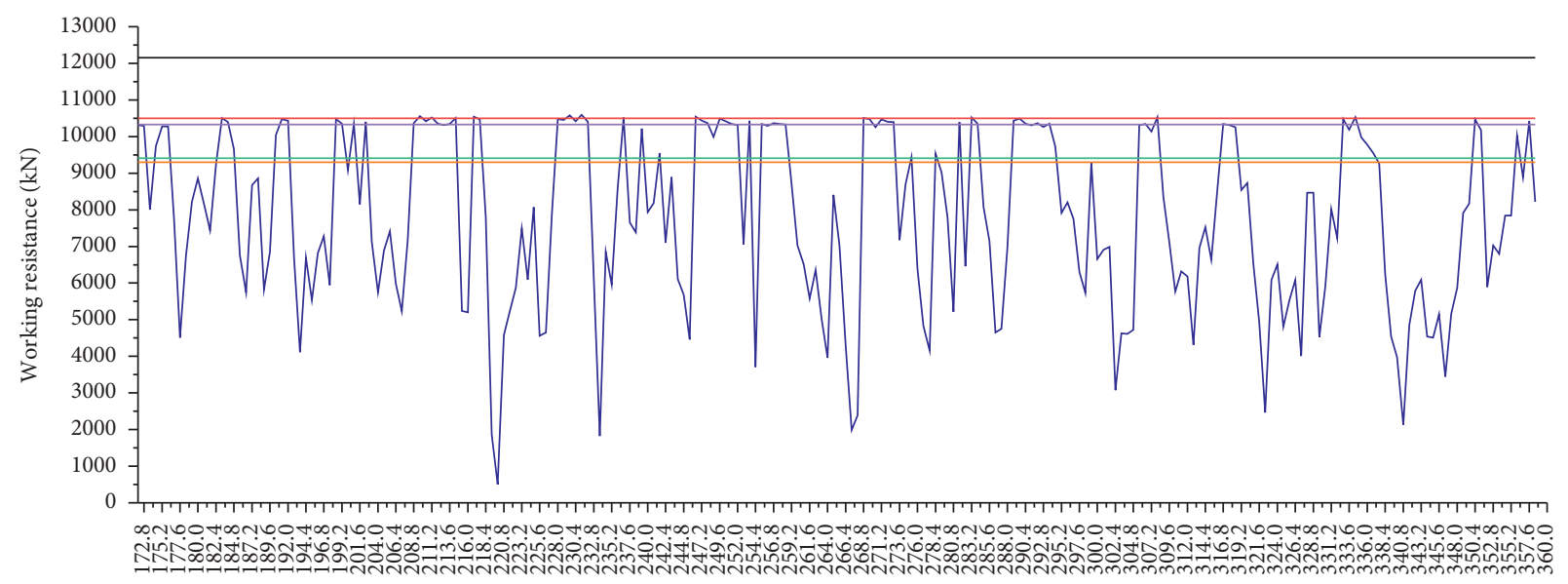

Propelling distance $(\mathrm{m})$

End of cycle resistance
Rated working resistance

13000

12000

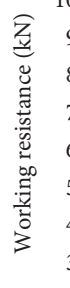

9000
8000
7000
6000
5000
4000
3000
2000
1000
0

Tाग

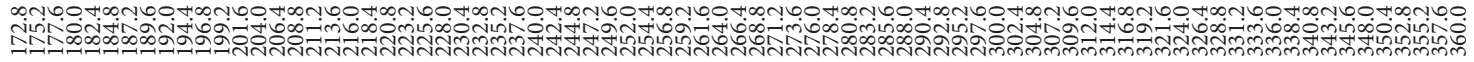

Propelling distance $(\mathrm{m})$

End of cycle resistance

- Actual rated working resistance

_ Mean resistance of 6 supports

_ Mean partial resistance of 6 supports

(b)

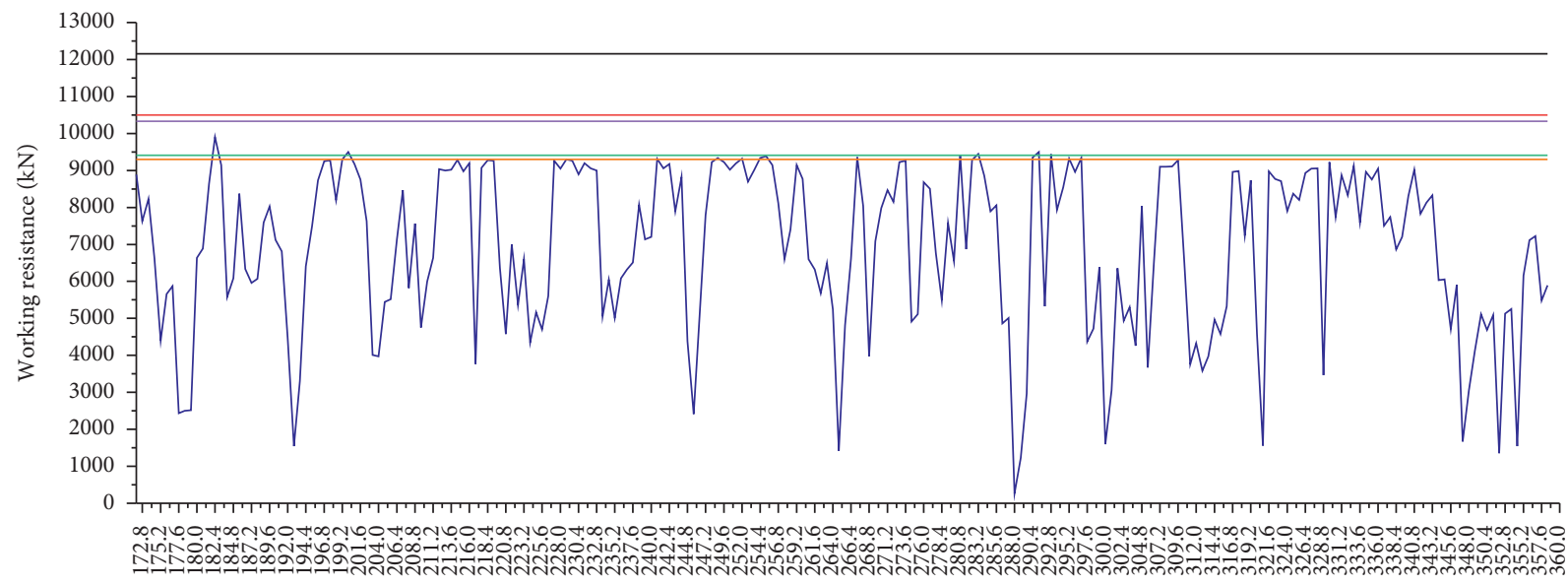

Propelling distance $(\mathrm{m})$

- End of cycle resistance

_ Rated working resistance __ctual rated working resistance
Mean resistance of 6 supports

(c)

Figure 11: Continued. 


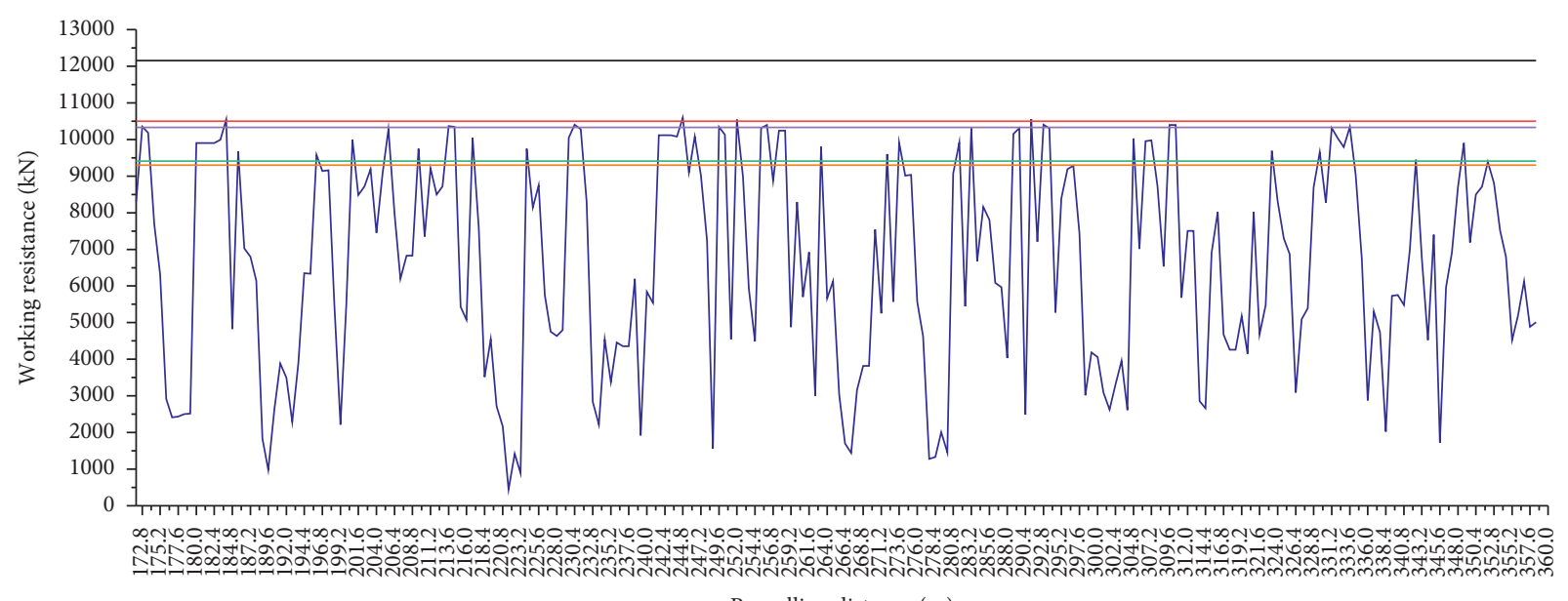

Propelling distance $(\mathrm{m})$

__ End of cycle resistance

_ Actual rated working resistance

_ Mean partial resistance of 6 supports

(d)

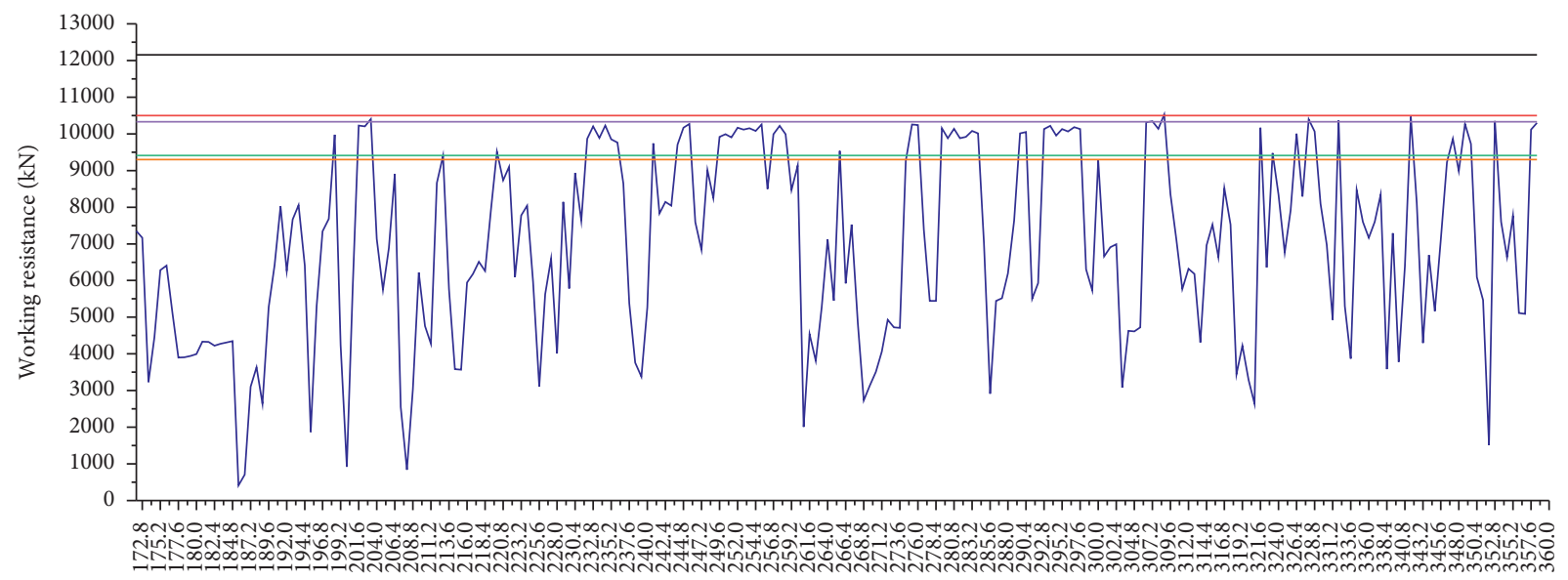

Propelling distance $(\mathrm{m})$

End of cycle resistance
Rated working resistance
_ Mean partial resistance of 6 supports __ Actual rated working resistance

(e)

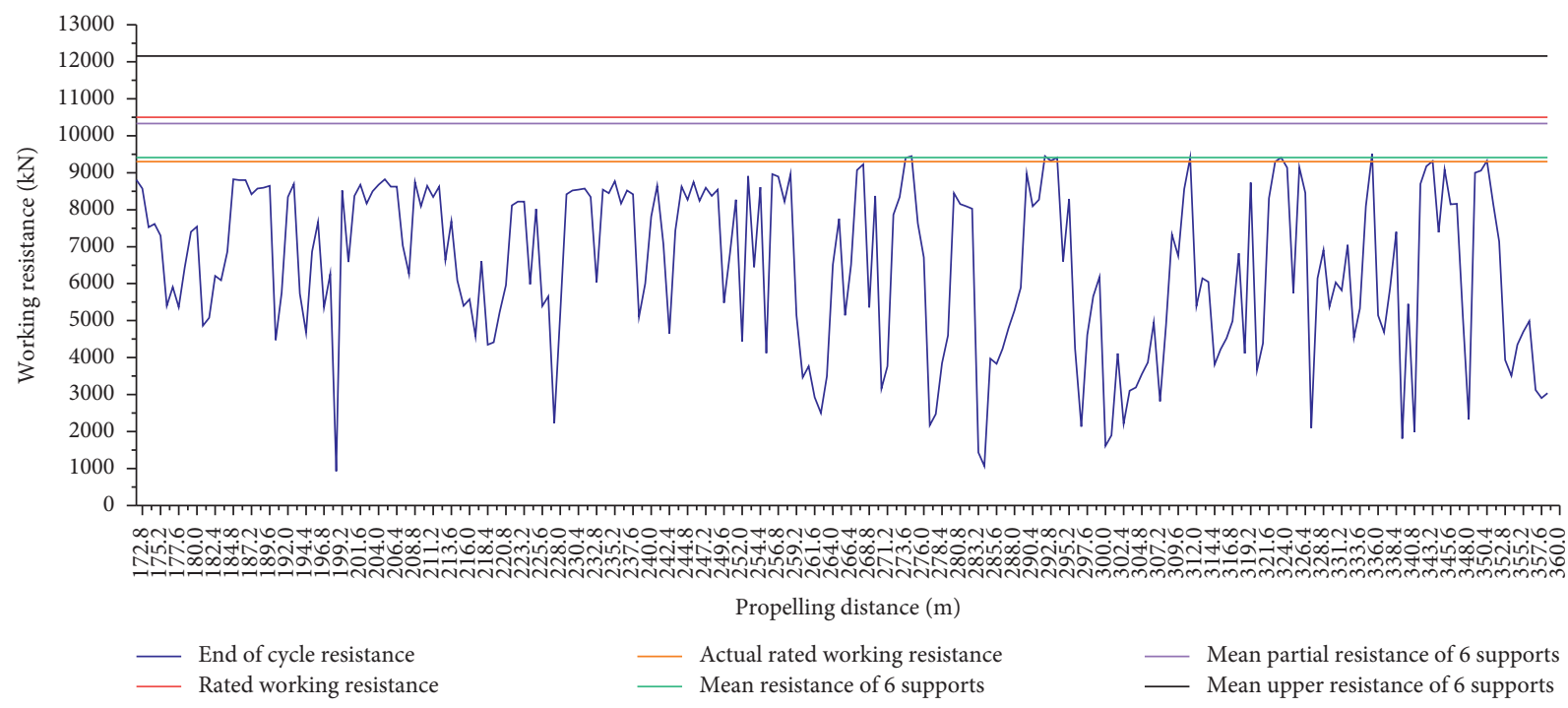

(f)

FIGURE 11: 5 kinds of working resistance relationship of 6 key supports: (a) 62\# support, (b) 64\# support, (c) 67\# support, (d) 89\# support, (e) 108\# support, and (f) 120\# support. 
TABLE 7: Ratio of end cycle resistance exceeding 5 resistance values for 6 key supports.

\begin{tabular}{|c|c|c|c|c|c|c|c|c|c|}
\hline \multirow{2}{*}{\multicolumn{2}{|c|}{ Resistance of support $(\mathrm{kN})$}} & \multirow{2}{*}{ Ratio type } & \multicolumn{6}{|c|}{ Overrun ratio (\%) } & \multirow{2}{*}{ Average overrun ratio (\%) } \\
\hline & & & $62 \#$ & $64 \#$ & $67 \#$ & 89\# & $108 \#$ & $120 \#$ & \\
\hline \multirow{2}{*}{1} & \multirow{2}{*}{$p=10500$} & $A_{1}$ & 5.55 & 0 & 0 & 1.71 & 0 & 0 & 1.21 \\
\hline & & $A_{2}$ & 13.95 & 0 & 0 & 3.29 & 0 & 0 & 2.87 \\
\hline \multirow{2}{*}{2} & \multirow{2}{*}{$p^{\prime}=9300$} & $A_{1}$ & 37.60 & 2.14 & 6.41 & 25.32 & 28.76 & 4.27 & 17.42 \\
\hline & & $A_{2}$ & 86.05 & 5.55 & 19.23 & 40.66 & 63.33 & 9.89 & 37.45 \\
\hline \multirow{2}{*}{3} & \multirow{2}{*}{$\bar{p}=9412$} & $A_{1}$ & 37.60 & 0.42 & 2.56 & 24.89 & 28.33 & 1.28 & 15.85 \\
\hline & & $A_{2}$ & 86.05 & 1.38 & 7.69 & 40.66 & 62.22 & 3.30 & 33.55 \\
\hline \multirow{2}{*}{4} & \multirow{2}{*}{$\bar{p}_{1}=10327$} & $A_{1}$ & 23.93 & 0 & 0 & 6.01 & 3.43 & 0 & 5.56 \\
\hline & & $A_{2}$ & 60.47 & 0 & 0 & 12.09 & 7.78 & 0 & 13.39 \\
\hline \multirow{2}{*}{5} & \multirow{2}{*}{$\bar{p}_{2}=12157$} & $A_{1}$ & 0 & 0 & 0 & 0 & 0 & 0 & 0.00 \\
\hline & & $A_{2}$ & 0 & 0 & 0 & 0 & 0 & 0 & 0.00 \\
\hline \multirow{2}{*}{\multicolumn{2}{|c|}{ Number of statistical cycles }} & $n$ & 86 & 72 & 78 & 91 & 90 & 91 & 84.67 \\
\hline & & $N$ & 234 & 233 & 233 & 234 & 233 & 234 & 233.50 \\
\hline
\end{tabular}

5.2.3. Comprehensive Check of Reasonable Working Resistance of Support in 103 Working Face. Combined with Tables 5 and 6, the reasonable working resistance of support in 103 working face can be checked:

(1) $r-p$ : during the periodic pressure, the effect of roof control is "good," and the value of $A_{1}$ and $A_{2}$ is small. When $p$ is reduced to $0.984 p=\bar{p}_{1}$, the values of $A_{1}$ and $A_{2}$ are greatly increased, so $r=p$ can be taken as a reasonable value, but it is in critical state.

(2) $r-p^{\prime}, r-\bar{p}$, and $r-\bar{p}_{1}$ : during the periodic pressure, the value of $A_{1}$ and $A_{2}$ is large, so $r=p^{\prime}, r-\bar{p}$, and $r-\bar{p}_{1}$ cannot be taken as a reasonable value.

(3) $r-\bar{p}_{2}$ : during the periodic pressure, the effect of roof control is "good," and the value of $A_{1}$ and $A_{2}$ is 0 , so $r$ $\bar{p}_{2}$ can be taken as a reasonable value.

(4) $R=p$ and $R=\bar{p}_{2}: R=10500 \sim 12157 \mathrm{kN}$ can be taken as the reasonable working resistance of support in 103 working face.

(5) According to the 4 years decline range of support resistance performance in 103 working face, if the working resistance of the new support is selected to the large value $R=12000 \mathrm{kN}$, it will be close to $10500 \mathrm{kN}$ after 4 years, and the effect of roof control is "good," and the value of $A_{1}$ and $A_{2}$ is small. The reasonable working resistance of the new support can be taken as $R=12000 \mathrm{kN}$.

5.3. Determination of Reasonable Working Resistance of Support in 105 Working Face of the 3-1 Coal Seam by Analogy Estimation Method. The new 105 working face and the 103 working face are belonged to the 3-1 coal seam, and their geological and mining conditions are similar. If the structural type of the new support is relatively unchanged, the analogy coefficient can be taken as 1, and the rated working resistance of the new support in 105 working face can be taken as $R=12000 \mathrm{kN}$.

\section{Conclusions and Discussion}

In this paper, the engineering problem of whether multiple service support needs to be replaced in 105 working face in the 3-1 coal seam is solved through the scientific evaluation of many factors. At the same time, a new method of determining the working resistance of support is proposed based on the measured data of dynamic pressure. The main conclusions are as follows:

(1) It is found that the resistance performance of multiple service support is obviously declined because the safety valve is opened in advance. The resistance loss rate of multiple service support is relatively large.

(2) The resistance performance of multiple service support has been declined by $18 \% \sim 24.8 \%$, and the resistance of multiple service support is insufficient. The total amount of roof subsidence of multiple coal cutting during the periodic pressure is calculated as $283 \mathrm{~mm}$ and the grade is medium. The support system performance of multiple service support under the influence of many fuzzy factors is evaluated as 63.31 points and level close to "poor". The multiple service supports cannot continue to be used in 105 working face.

(3) The reasonable working resistance of support in 103 working face is optimized to $F=12000 \mathrm{kN}$ by the new method based on dynamic pressure, and the reasonable working resistance of support in the new 105 working face is determined as $F=12000 \mathrm{kN}$.

Generally speaking, the paper establishes the support performance evaluation system. Based on the measured dynamic pressure data, a method to optimize the working resistance of support is proposed. Although the corresponding engineering problems have been solved, there are still some limitations and the necessity of further research:

(1) Firstly, the paper evaluates the support performance mainly from the perspective of the support resistance performance, and the mechanical performance of the support also affects the support capacity to a great extent. Due to the complexity of the mechanical structure of the support, this paper does not study it. In the future, the mechanical damage factors should be considered to establish a comprehensive performance evaluation system. 
(2) Secondly, the prediction of support resistance performance decline analyzed in this paper only gives the approximate estimation from the perspective of statistics. The next step is to carry out the accurate analysis of support resistance performance decline prediction and give the corresponding prediction formula.

\section{Data Availability}

All the field measured data in this paper are measured in 103 working face of Gaotouyao coal mine of Huaneng Group. The datasets used or analysed during the current study are available from the corresponding author on reasonable request.

\section{Conflicts of Interest}

The authors declare no conflicts of interest.

\section{Acknowledgments}

This study was financially supported by the National Natural Science Foundation of China (no. 51974317), the Yue Qi Distinguished Scholar Project (800015Z1138), China University of Mining and Technology, Beijing, and the Fundamental Research Funds for the Central Universities (800015J6).

\section{References}

[1] Z. H. Zhao, M. Z. Zhang, and Q. Ma, "Deviation effect of coaxiality on the rock brazilian split," Advances in Mathematical Physics, vol. 2020, Article ID 5782457, 8 pages, 2020.

[2] G. Zhang, L. Chen, Z. Wen et al., "Squeezing failure behavior of roof-coal masses in a gob-side entry driven under unstable overlying strata," Energy Science \& Engineering, vol. 8, no. 7, pp. 2443-2456, 2020.

[3] B. Shen, "Coal mine roadway stability in soft rock: a case study," Rock Mechanics and Rock Engineering, vol. 47, no. 6, pp. 2225-2238, 2014.

[4] L. Li, X. He, Y.-Q. Chen, Y.-C. Li, C.-H. Shi, and Y.-P. Zhu, "Influence of different propulsion speeds on the characteristics of mine pressure in the fully mechanized caving face during rotary stage," Geotechnical and Geological Engineering, vol. 37, no. 5, pp. 3937-3947, 2019.

[5] Q. Ma, Y. L. Tan, X. S. Liu et al., "Effect of coal thicknesses on energy evolution characteristics of roof rock-coal-floor rock sandwich composite structure and its damage constitutive model," Composites Part B: Engineering, 2020.

[6] C. X. Wang, B. T. Shen, J. T. Chen et al., "Compression characteristics of filling gangue and simulation of mining with gangue backfilling: an experimental investigation," Geomechanics and Engineering, vol. 20, no. 6, pp. 485-495, 2020.

[7] W.-D. Wu, J.-B. Bai, X.-Y. Wang, S. Yan, and S.-X. Wu, "Numerical study of failure mechanisms and control techniques for a gob-side yield pillar in the sijiazhuang coal mine, China," Rock Mechanics and Rock Engineering, vol. 52, no. 4, pp. 1231-1245, 2019.

[8] G. C. Zhang, Y. L. Tan, S. J. Liang, and H. G. Jia, "Numerical estimation of suitable gob-side entry filling wall width in a high gassy longwall mining panel," International Journal of Geomechanics, vol. 18, no. 8, Article ID 040180091, 2018.
[9] G. C. Zhang, Z. J. Wen, and S. J. Liang, "Ground response of a gob-side entry in a longwall panel extracting $17 \mathrm{~m}$-thick coal seam: a case study," Rock Mechanics and Rock Engineering, vol. 53, no. 2, pp. 497-516, 2019.

[10] C. Wang, Y. Wang, and S. Lu, "Deformational behaviour of roadways in soft rocks in underground coal mines and principles for stability control," International Journal of Rock Mechanics and Mining Sciences, vol. 37, no. 6, pp. 937-946, 2000.

[11] Z. Q. Song, Y. J. Jiang, and J. K. Liu, “Theory and model of practical method of mine pressure control," Coal Science ఓTechnology Magazine, vol. 2017, no. 2, pp. 1-10, 2017, in Chinese.

[12] S. L. WuS. L. Liu et al., "Study on roof structure model and support-surrounding rock relationship at fully-mechanized coal mining face," Journal of Shandong University of Science and Technology(Natural Science), vol. 3551 pages, 2016, in Chinese.

[13] W. Liu, L. Pang, B. Xu, and X. Sun, "Study on overburden failure characteristics in deep thick loose seam and thick coal seam mining," Geomatics, Natural Hazards and Risk, vol. 11, no. 1, pp. 632-653, 2020.

[14] Z. Q. SongJ. Hao et al., "An overview of connotation and development of practical ground pressure control theory," Journal of Shandong University of Science and Technology(Natural Science), vol. 38, no. 1, pp. 1-15, 2019, in Chinese.

[15] M. G. Qian and H. C. Li, "The movement of overlying strata in longwall mining and itseffect on ground pressure," Journal of China Coal Society, vol. 2, pp. 1-12, 1982, in Chinese.

[16] Q. X. HangJ. Xu et al., "Determination of support setting load of large-mining-height longwall face in shallow coal seam," Journal of Mining \& Safety Engineering, vol. 36, no. 3, pp. 491-496, 2019, in Chinese.

[17] D.-Z. Kong, Z.-B. Cheng, and S.-S. Zheng, "Study on the failure mechanism and stability control measures in a largecutting-height coal mining face with a deep-buried seam," Bulletin of Engineering Geology and the Environment, vol. 78, no. 8, pp. 6143-6157, 2019.

[18] Z. B. ChengS. L. Yang et al., "Support working resistance determined on top-coal caving face based on coal-rock combined body," Geomechanics and Engineering, vol. 19, no. 3, pp. 255-268, 2019.

[19] G. C. Wang, L. Wang, and Y. Guo, "Determining the support capacity based on roof and coal wall control," Journal of the China Coal Society, vol. 39, no. 8, pp. 1619-1624, 2014, in Chinese.

[20] D. Z. Kong and S. L. Yang, "Determination of support capacity based on coal face stability control," Journal of the China Coal Society, vol. 42, no. 3, pp. 590-596, 2017, in Chinese.

[21] R. A. B. Almeida, A. P. V. Urgueira, and N. M. M. Maia, "Evaluation of the performance of three different methods used in the identification of rigid body properties," Shock and Vibration, vol. 15, no. 3-4, pp. 467-479, 2008.

[22] M. Cao, E. A. Chi, J. Liu et al., "An energy-based safety evaluation index of blast vibration," Shock and Vibration, vol. 2015, no. 5, pp. 698193.1-698193.9, 2015.

[23] B. Rusmir, Z. Ninoslav, S. G. Alexandros et al., "Feature extraction using discrete wavelet transform for gear fault diagnosis of wind turbine gearbox," Shock and Vibration, vol. 2016, Article ID 6748469, 10 pages, 2016.

[24] R. Pierrard and J. P. Poli, "A fuzzy close algorithm for mining fuzzy association rules," in Proceedings of the International 
Conference on Information Processing \& Management of Uncertainty in Knowledge-Based Systems, Theory and Foundations, vol. 854, pp. 88-89, Springer, Cádiz, Spain, 2018.

[25] Islavath and S. Rao, "Life cycle analysis and damage prediction of a longwall powered support using 3D numerical modelling techniques," Arabian Journal of Geosciences, vol. 12, no. 17, p. 441, 2019.

[26] H. W. Liu, G. B. Pu, Y. H. Du, and P. Zhang, "Finite element analysis of static strength and fatigue strength of hydraulic shield support," Advanced Materials Research, vol. 332-334, pp. 2161-2165, 2011.

[27] X. G. Li, X. F. Wang, and Y. Fang, "Cause-chain analysis of coal-mine gas explosion accident based on Bayesian network model," Cluster Computing, vol. 22, no. 1, 2019.

[28] Y.-C. Tsai and A. Chatterjee, "Comprehensive, quantitative crack detection algorithm performance evaluation system," Journal of Computing in Civil Engineering, vol. 31, no. 5, Article ID 04017047, 2017.

[29] Y. B. Du, "Supporting condition acquisition and fuzzy comprehensive evaluation method for hydraulic support," Journal of the China Coal Society, vol. 42, pp. 260-266, 2017, in Chinese.

[30] Z. H. Xu and S. C. Li, "Risk assessment of water or mud inrush of karst tunnels based on analytic hierarchy process," Rock and Soil Mechanics, vol. 32, no. 6, 2011, in Chinese.

[31] G. F. Wang and Y. H. Pang, "Hydraulic support and coal wall coupling relationship in ultra large height mining face," Journal of China Coal Society, vol. 42, no. 2, pp. 518-526, 2017, in Chinese.

[32] G. F. Wang and Y. H. Pang, "Full-mechanized coal mining and caving mining method evaluation and key technology for thick coal seam," Journal of China Coal Society, vol. 43, no. 1, pp. 33-42, 2018, in Chinese.

[33] B. Li, Y. P. Liang, and Q. L. Zou, "Determination of working resistance based on movement type of the first subordinate key stratum in a fully mechanized face with large mining height," Energy Science Engineering, vol. 7, pp. 777-798, 2019.

[34] G. S. P. Singh and U. K. Singh, "Prediction of caving behavior of strata and optimum rating of hydraulic powered support for longwall workings," International Journal of Rock Mechanics and Mining Sciences, vol. 47, no. 1, pp. 1-16, 2010.

[35] O. Taylan, A. O. Bafail, R. M. S. Abdulaal, and M. R. Kabli, "Construction projects selection and risk assessment by fuzzy AHP and fuzzy TOPSIS methodologies," Applied Soft Computing, vol. 17, pp. 105-116, 2014.

[36] J. J. Zhang, "Fuzzy analytical hierarchy process," Fuzzy Systems and Mathematics, vol. 14, no. 2, pp. 80-88, 2000.

[37] L. C. Leung and D. Cao, "On consistency and ranking of alternatives in fuzzy AHP," European Journal of Operational Research, vol. 124, no. 1, pp. 102-113, 2010.

[38] H. L. Zhang, "The safety evaluation study of the ventilation system in coal mine based on fuzzy analytical hierarchy process method," Master's thesis, Inner Mongolia University of Science and Technology, Hefei, China, 2014. 